\title{
Docking-designed Green Synthesis and In-Vitro Anticancer Studies of New Binuclear Se-N- Heterocyclic Carbene Adducts and their Azolium Salts
}

\section{Muhammad Atif}

University of Agriculture Faisalabad

Mansoureh Nazari V

Universiti Sains Malaysia

Mohamed B Khadeer Ahamed

Eman Biodiscoveries Sdn. Bhd.

Maryam Aslam

Government College Women University Faisalabad

Aman Shah Abdul Majid

Quest International University Perak

Muhammad Adnan lqbal ( $\sim$ muhammad.adnan.iqbal.u.a.f@gmail.com )

University of Agriculture Faisalabad

\section{Research Article}

Keywords: Selenium adducts, Binuclear benzimidazolium salts, Se-NHC, Molecular docking, Breast cancer (MCF-7), Cervical cancer (Hela), Retinal Ganglion cancer (RGC-5)

Posted Date: July 8th, 2021

DOI: https://doi.org/10.21203/rs.3.rs-678554/v1

License: (c) (1) This work is licensed under a Creative Commons Attribution 4.0 International License. Read Full License 


\section{Abstract}

Two binuclear selenium adducts (5 and $\mathbf{6}$ ) were designed using molecular docking approach while finding their promising interaction to four angiogenic factor-proteins including COX-1 (Cyclooxygenase-1), VEGF-A (vascular endothelial growth factor A), HIF (Hypoxia-inducible factor) and EGF (human epidermal growth factor). They were consequently synthesized using In-situ coordination approach. The green synthetic approach was employed for coordination as it was carried out in water instead of organic solvents. The synthesized adducts as well as their respective bis-benzimidazolium salts ( 2 and $\mathbf{4})$ were confirmed by ${ }^{1} \mathrm{H}$ and ${ }^{13} \mathrm{C}-\mathrm{NMR}$ along with FT-IR spectroscopy. The both were, then, subjected to In-vitro anticancer activities against breast adenocarcinoma cell line (MCF-7), cervical cancer cell line (Hela), mouse melanoma cell line (B16F10) and retinal ganglion cell line (RGC-5) using MTT assay while comparing their activities with a commercially established standard-drug 5-Fluorouracil. However, the exceptional activities of both adducts and bis-benzimidazolium salts were explored.

\section{Introduction}

Selenium is a nutritional supplement and its analogues are biocompatible-therapeutics [1]. Moreover, antiinfective potential of its adducts with organic compounds is widely reported in literature which is due to its probable bioavailability at the target site [2] wherein its adducts get hydrolyzed to consequently produce ionized selenium inside cellular membrane. Its pattern of hydrolysis and ionization offer versatility of its functional role for different biological targets. For instance, m-tri-fluoromethyl-diPhenyl diselenide is used to treat mechanical allodynia; selenomethionine (SeMet) for human colorectal cancer and bis-selenide 3-(4-fluoroPhenylselenyl)-2,5-diPhe-nylselenoPhene for depression-related behavior [35]. Moreover, many selenium analogues are under clinical trials as ebselen, a selenium heterocyclic compound, is in phase II of clinical trials to treat the retrieval of hearing loss and some types of cancers [6]. So the modulated hydrolysis of selenium adducts with respect to biological target is often considered a subject of its activity.

A better modulation-approach implies its coordination with $\mathrm{N}$-Heterocyclic carbene analogues which can endow a potential permeability over a wide range of lipophilicity to better cross membrane barriers [7]. In this way, it becomes capable to show chemo-preventive activities like antioxidant, anti-depressant, antineoplastic anti-inflammatory, anti-neuro-degenerative, antimicrobial and anti-viral activities [8, 9]. Initially, mononuclear selenium $\mathrm{N}$-Heterocyclic carbenes analogues were synthesized and tested in this pursuit. Recently, binuclear $\mathrm{N}$-Heterocyclic carbene analogue were synthesized to further advance its versatility in their stability and lipophilicity. But a little advancement was made in context. The present work was directed, not only, to synthesize some more binuclear Se- $\mathrm{N}$-Heterocyclic carbene adducts, but also to promote a green synthetic approach for their synthesis while making use water as reaction media instead of organic solvents.

\section{Experimental}




\subsection{Designing of Anticancer Se-NHC Adduct}

Molecular docking approach to design potential anticancer Se-NHC Adduct was employed wherein target protein preparation was made while downloading python language from www.python.com; Bio Via from http://accelrys.com; Molecular graphics laboratory (MGL) from http://mgltools.scripps.edu; Discovery studio visualizer 2017 from http://accelrys.com; Chem3D from https:// acms.ucsd.edu; and AutoDock 4.2 from http://autodock.scripps.edu. The selected software was employed to select three dimensional X-ray crystallographic structure of HIF, VEGF-A, EGF and COX1 proteins as target for designed chemical analogues. The crystallographic structures were selected from Protein Data Bank-PDB (www.rvcsb.org/pdb) using PDB ID: 4KZN for VEGF-A; PDB ID: 1EQH for COX1; PDB ID: 1JL9 for EGF and PDB ID: $1 Y \mathrm{YCl}$ for HIF, their representations are shown in (Fig. 1) [56]. The study was resumed while deleting all non-essential entities like small molecules, water molecule, nonpolar hydrogens, heteroatoms, non-standard residues and lone pairs were deleted and adding hydrogens in target receptor molecule. Dock Prep was used to optimize geometric fitting and to evaluate minimum energy a built-in tool for structures preparation before docking employed.

Ligand preparation in docking was accomplished while selecting two designed compounds from crystallography with available with identified structure of salts were used by Pubchem to create their sdf format which was changed to PDB format using Pymol. The starting structures were prepared using AutoDock tools, water molecule was eliminated, polar hydrogen and Kollman charges were added to the protein starting structure. Grid box was set with the size of $126 \times 126 \times 126 \AA$ with the grid spacing of $0.375 \AA$ at the binding site. The starting structure both salts namely V and VI were constructed using BioVia draw while Sunitinib and 5-Flourouracil were selected as positive control getting their structures from Pubchem website Gasteiger. The optimized ligands were assigned with charges using Autodock tools. 100 docking runs were monitored with crossover rate of 0.8 and mutation rate of 0.02 . Moreover, 250 randomly placed individual was the population size. Lamarckian Genetic algorithm was used in searching algorithm with a translational step of $0.2 \AA$, a quaternion step of $5 \AA$ and a torsion step of $5 \AA$.

\subsection{Synthesis of designed analogues}

All reagents and chemicals including benzimidazole as precursor; dimethyl sulfoxide (DMSO) and 1,4dioxane as reaction media; $o$-xylene dibromide, $n$-hexyl and n-octyl bromide as alkylating agents; selenium powder for coordination were supplied by Sigma Aldrich and they were used as received without any sort of purification unless otherwise stated. All reactions were accomplished in ordinary laboratory conditions. Bisbenzimidazolium salts ( 2 and 4 ) synthesized by their respective $\mathrm{N}$-alkylation of benzimidazole. Selenium $N$-Heterocyclic carbene adducts ( 5 and 6 ) were synthesized by $I n$-situ approach according to reported procedures as shown in Scheme-1 $[8,10]$. Melting points of synthesized compounds by Stuart Melting Point method SMP11. Their spectroscopic confirmation was made by Fourier transform Infrared spectroscopic analysis using Perkin-Elmer 2000 spectrophotometer; $\mathrm{H}^{1}$-NMR and $\mathrm{C}^{13}$-NMR analysis by Bruker Advance 500. For the assessment of In-Vitro anticancer activities, reagents for cell culturing, HIFBS (heat inactivated foetal bovine Serum) and Trypsin, Dulbecco's modified were supplied 
by Gibco, USA; Eagle and RPMI 1640 medium, and were purchased from GIBCO, UK. All cell-lines including Hela, MCF-7, RGC-5 and B16F10 were purchased from ATCC, USA and were used as per [11].

Reaction Scheme-I

\subsection{Synthesis of binuclear benzimidazolium salts \\ 2.3.1 Synthesis of 2 (1-hexyl-3-(2-((3-hexyl-1H- benzo[d]imidazol-3-ium-1-yl)methyl) benzyl)-1H- benzo[d]imidazol-3-ium bromide)}

Firstly, 1-hexyl-1 H-benzo[d]imidazole (Compound 1) was prepared while treating benzimidazole $(1 \mathrm{~g}, 8.46$ $\mathrm{mmol}), \mathrm{KOH}(0.71 \mathrm{~g}, 12.40 \mathrm{mmol})$ and hexyl bromide $(1.19 \mathrm{~mL}, 8.46 \mathrm{mmol})$ in the presence of $(20 \mathrm{~mL})$ dimethyl sulfoxide (DMSO) as a solvent stirred for three hours at room temperature which was extracted by water-chloroform system to consequently dried with a yield $94.4 \%$ in form of thick yellowish fluid. Compound 1 was again subjected to further $\mathrm{N}$-alkylation by 0 -xylene dibromide to produce 1 -hexyl-3-(2((3-hexyl-1 H-benzo[d]imidazol-3-ium-1-yl)methyl) benzyl)-1 H-benzo[d]imidazol-3-ium bromide (Compound 1) wherein it was treated with $(2.2 \mathrm{~g}, 7.9 \mathrm{mmol})$ of ortho-xylene dibromide in $25 \mathrm{~mL}$ of 1,4-dioxane under reflux for 24 hours. Slight creamy precipitates were emerged which were isolated by decantation and were washed with fresh 1,4-dioxane and dried getting a yield of $75 \%$ with melting point $246{ }^{\circ} \mathrm{C}$. The product was consequently confirmed as: FT-IR $\left(\mathrm{KBr}_{\mathrm{cm}}{ }^{-1}\right)$ : 3410, $3390\left(\mathrm{C}_{\text {aliph }}-\mathrm{N}_{\text {benzimi }}\right), 3080,3030\left(\mathrm{C}-\mathrm{H}_{\text {arom }}\right)$, 2947, 2825, 2900, 2890 (C-H aliph $), 1605,1573,1517$ ( $\left.\mathrm{C}_{\text {arom }} \mathrm{C}_{\text {arom }}\right), 1214,1407,1417,1426\left(\mathrm{C}_{\text {arom }^{-}}{ }^{-}\right.$ $\left.\mathrm{N}_{\text {benzimi }}\right) .{ }^{1} \mathrm{HNMR}\left(500 \mathrm{MHz}, d_{6}\right.$-DMSO) $\delta \mathrm{ppm}: 0.85\left(\mathrm{t}, J=7.0 \mathrm{~Hz}, 6 \mathrm{H}, 2 \times \mathrm{CH}_{3}\right), 1.3-1.4(\mathrm{br} . \mathrm{m}, 10 \mathrm{H}, 5 \times$ $\left.\mathrm{CH}_{2}\right), 3.5\left(\mathrm{~s}, 4 \mathrm{H}, 2 \times \mathrm{N}-\mathrm{CH}_{2}-\mathrm{Ar}\right), 4.51\left(\mathrm{t}, J=7.0 \mathrm{~Hz}, 4 \mathrm{H}, 2 \times \mathrm{NCH}_{2}-\mathrm{R}\right), 7.20$ (q, 2H, $\left.\mathrm{Ar} 2 \times \mathrm{CH}\right), 7.37$ (q, 2H, $\mathrm{Ar} 2$ $\times \mathrm{CH}), 7.64(\mathrm{t}, \mathrm{J}=7.5 \mathrm{~Hz}, 2 \mathrm{H}, \operatorname{Ar} 2 \times \mathrm{CH}), 7.66(\mathrm{t}, \mathrm{J}=8.0 \mathrm{~Hz}, 2 \mathrm{H}, \mathrm{Ar} 2 \times \mathrm{CH}), 8.1(\mathrm{~d}, \mathrm{~J}=8.0 \mathrm{~Hz}, 2 \mathrm{H}, \mathrm{Ar} 2 \times \mathrm{CH})$, $9.89(\mathrm{~s}, 2 \mathrm{H}, 2 \times \mathrm{NCHN}) ; 13 \mathrm{C}\{1 \mathrm{H}\} \mathrm{NMR}\left(125.5 \mathrm{MHz}, \mathrm{DMSO}-\mathrm{d}_{6}\right) \delta \mathrm{ppm:} 14.6\left(\mathrm{CH}_{3}\right), 22.4,25.9,29.01,39.9(5$ $\left.\times \mathrm{CH}_{2}\right), 47.3\left(\mathrm{R}-\mathrm{CH}_{2}-\mathrm{N}\right), 48.05\left(\mathrm{Ar}-\mathrm{CH}_{2}-\mathrm{N}\right), 114.6-132.4(\mathrm{Ar}-\mathrm{C})$ and $139.8(\mathrm{NCN})$. Anal. Cal. For:

C34H45Br2N4O: C, 80.27; H, 8.72; N, 11.1\%. Found: C, 77.2; H, 7.5; N, 10.17\%.

\subsubsection{Synthesis of 4 (1-octyl-3-(2-((3-octyl-1H- benzo[d]imidazol-3-ium-1-yl)methyl)benzyl)-1H- benzo[d]imidazol-3-ium bromide)}

The synthesis of compound $\mathbf{4}$ was followed by its retrosynthesis in same way as that of compound-2 only the difference was the reaction of n-octyl bromide with benzimidazole to get compound $\mathbf{3}$. Then $\mathbf{3}$ was reacted with equimolar ortho-xylene dibromide in same to get 4 which was prepared with 90 percent yield and was appeared in form of white crystalline powder with melting point $204^{\circ} \mathrm{C}$. FT-IR $\left(\mathrm{KBr}, \mathrm{v}_{\text {max }}\right.$ $\left.\mathrm{cm}^{-1}\right)$ : 3403, $3378\left(\mathrm{C}_{\text {aliph }} \mathrm{N}_{\text {benzimi }}\right) ; 3085,3055\left(\mathrm{C}-\mathrm{H}_{\text {arom }}\right) ; 2983,2894,2813\left(\mathrm{C}-\mathrm{H}_{\text {aliph }}\right) ; 1600,1542$ (C$\left.\mathrm{H}_{\text {aliph }}\right) ; 1173,1406,1423,1488\left(\mathrm{C}_{\text {arom }}-\mathrm{N}_{\text {benzimi }}\right) .{ }^{1} \mathrm{H}$ NMR (500 MHz, $d_{6}$-DMSO) $\delta \mathrm{ppm:} 0.83$ (t, J=7.0 Hz, $\left.6 \mathrm{H}, 2 \times \mathrm{CH}_{3}\right), 1.2-1.35\left(\mathrm{br} . \mathrm{m}, 2 \mathrm{H}, 10 \times \mathrm{CH}_{2}\right.$ ), 1.88 (qnt, $\left.J=7.5 \mathrm{~Hz}, 4 \mathrm{H}, 2 \times \mathrm{CH}_{2}\right), 4.56(\mathrm{t}, J=7.5 \mathrm{~Hz}, 4 \mathrm{H}, 2 \times$ 


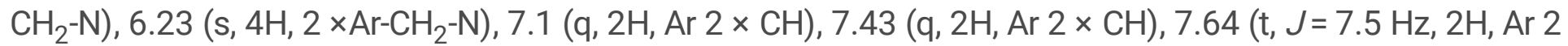
$\times \mathrm{CH}), 7.7(\mathrm{t}, J=7.7 \mathrm{~Hz}, 2 \mathrm{H}, \operatorname{Ar} 2 \times \mathrm{CH}), 8.03(\mathrm{~d}, J=8.3 \mathrm{~Hz}, 2 \mathrm{H}, \mathrm{Ar} 2 \times \mathrm{CH}), 8.2(\mathrm{~d}, J=8.5 \mathrm{~Hz}, 2 \mathrm{H}, \mathrm{Ar} 2 \times \mathrm{CH})$, $10.12(\mathrm{~s}, 2 \mathrm{H}, 2 \times \mathrm{NCHN}) ; 13 \mathrm{C}\{1 \mathrm{H}\} \mathrm{NMR}(125.5 \mathrm{MHz}$, DMSO-d 6$) \delta \mathrm{ppm:} 14.11\left(\mathrm{CH}_{3}\right), 21.2,26.1,25.8(3 \times$

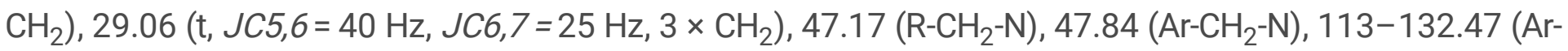
C) and $143.12(\mathrm{NCN})$. Anal. Cal. For: C38H54Br2N4O: C, 61.54; H, 7.20; N, 7.55\%. Found: C, 61.43; H, 7.17; $\mathrm{N}, 7.46 \%$.

\subsection{Synthesis of Binuclear Se-N-Heterocyclic Carbene (Se- NHC) Compounds}

Se-NHCs were synthesized using In-situ synthetic approach wherein $\mathbf{2}$ and $\mathbf{4}$ were coordinated to elemental selenium almost simultaneously after the production of $\mathrm{N}$-Heterocyclic carbene ligand from bis-benzimidazolium salts in alkaline aqueous conditions as per reported procedure wherein both of 5 and 6 adducts were synthesized by 3-5 hour stirring in reflux apparatus. When the products in form of insoluble mass along with unreacted dispersed-selenium particles started sticking to the walls of reaction flask and when there was no more aggregation of insoluble mass was observed the reaction was stopped. The hot reaction mixture was passed through the filtration apparatus, the insoluble mass (crudeproduct) retained on filter paper which was washed with fresh hot water several times so as to remove all of unreacted ligand and alkali molecules. When all of water was evaporated from product-contain filtration apparatus, fresh DMSO was poured so as to solubilize and pass the pure selenium adduct from filter paper to flask [8].

\subsubsection{Synthesis of $5\left(3,3^{\prime}-(1,2-\right.$ Phenylenebis(methylene))bis(1-hexyl-1H- benzo[d]imidazole-2(3H)-selenone)}

Adduct- 5 was obtained with $78 \%$ yield in form of colorless to yellowish thick fluid and it was confirmed as

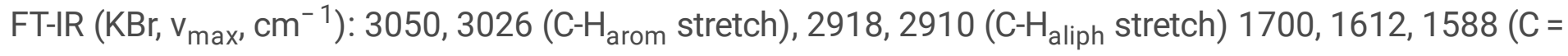
$\mathrm{C}_{\text {arom }}$ stretch), 1478, 1444, 1408, $1340\left(\mathrm{CH}_{2}\right.$-bending). ${ }^{1} \mathrm{H}$ NMR (500 MHz, $d_{6}$-DMSO) $\delta$ ppm: 0.83, 0.84 (t, $\left.\mathrm{J}=7.5 \mathrm{~Hz}, 6 \mathrm{H}, 2 \times \mathrm{CH}_{3}\right), 1.08-1.69\left(2 \mathrm{H}, \mathrm{br} . \mathrm{m}, 10 \times \mathrm{CH}_{2}\right), 1.91$ (qnt, $\left.4 \mathrm{H}, 2 \times \mathrm{CH}_{2}\right), 3.34(\mathrm{t}, \mathrm{J}=7.5 \mathrm{~Hz}, 4 \mathrm{H}, 2$ $\left.\times \mathrm{N}-\mathrm{CH}_{2}-\mathrm{R}\right), 5.41,5.26(\mathrm{~s}, 4 \mathrm{H}, 2 \times \mathrm{N}-\mathrm{CH} 2-\mathrm{Ar}), 7.08(\mathrm{~s}, 4 \mathrm{H}, \mathrm{Ar}-\mathrm{H}), 7.05$ (sext, 4H, Ar-H), 7.03 (d, J = 8.0 Hz, 2H, Ar-H,), 8.06 (d, J = 8.0 Hz, 4H, Ar-H), $8.16(\mathrm{~s}, 2 \mathrm{H}, 2 \times \mathrm{NCHN}) ;{ }^{13} \mathrm{C}\left\{{ }^{1} \mathrm{H}\right\} \mathrm{NMR}\left(125.75 \mathrm{MHz}, d_{6}-\mathrm{DMSO}\right) \delta \mathrm{ppm}$ : $16.5\left(\mathrm{CH}_{3}\right), 22.50,27.89\left(\mathrm{CH}_{2}\right), 28.15,28.23,28.27(\mathrm{JC} 4 / 5=13.9 \mathrm{~Hz}, \mathrm{JC} 5 / 6=2.5 \mathrm{~Hz}), 31.11\left(\mathrm{CH}_{2}\right), 46.58$ $\left(\mathrm{N}-\mathrm{CH}_{2}-\mathrm{R}\right), 48.43\left(\mathrm{~N}-\mathrm{CH}_{2}-\mathrm{Ar}\right), 114.37(\mathrm{~d}, \mathrm{~J}=11.2 \mathrm{~Hz}, \mathrm{Ar}-\mathrm{C}), 121.33(\mathrm{~J}=2.5 \mathrm{~Hz}), 127.65,129.40,131.77$, 134.76 (Ar-C), 153 (C-Se). Anal. Calcd: C, 61.44; H, 6.37; N, 8.43\%. Found: C, 59.21; H, 5.87; N, 6.89\%.

\subsubsection{Synthesis of $6\left(3,3^{\prime}-(1,2-\right.$ Phenylenebis(methylene))bis(1-octyl-1 H-benzo[d]imidazole- 2(3H)-selenone)}


Compound 6 was also synthesized as per general given methodology, it was appeared was obtained with $78 \%$ yield in form of light yellowish sticky fluid. FT-IR $\left(\mathrm{KBr}, \mathrm{v}_{\max }, \mathrm{cm}^{-1}\right): 3053,3023$ (C- $\mathrm{H}_{\text {arom }}$ stretch), 2921, 2907 (C- $\mathrm{H}_{\text {aliph }}$ stretch) 1703, 1609, 1591 ( $\mathrm{C}=\mathrm{C}_{\text {arom }}$ stretch), 1481, 1441, 1411, $1337\left(\mathrm{CH}_{2}\right.$-bending). ${ }^{1} \mathrm{H}$ NMR (500 MHz, DMSO-d $\left.{ }_{6}\right) \delta$ ppm: 0.811, $0.825\left(\mathrm{t}, \mathrm{J}=7.5 \mathrm{~Hz}, 6 \mathrm{H}, 2 \times \mathrm{CH}_{3}\right), 1.081-1.669(28 \mathrm{H}$, br.m, $10 \times$ $\mathrm{CH}_{2}$ ), 1.922 (qnt, 4H, $2 \times \mathrm{CH}_{2}$ ), $3.46\left(\mathrm{t}, \mathrm{J}=7.5 \mathrm{~Hz}, 4 \mathrm{H}, 2 \times \mathrm{N}-\mathrm{CH}_{2}-\mathrm{R}\right), 5.22,5.28(\mathrm{~s}, 4 \mathrm{H}, 2 \times \mathrm{N}-\mathrm{CH} 2-\mathrm{Ar}), 7.008$ (s, 4H, Ar-H), 7.045 (sext, 4H, Ar-H), 7.063 (d, J = 8.0 Hz, 2H, Ar-H,), 8.046 (d, J = 8.0 Hz, 4H, Ar-H), 8.16 (s, $2 \mathrm{H}, 2 \times \mathrm{NCHN}) ;{ }^{13} \mathrm{C}[12] \mathrm{NMR}\left(125.75 \mathrm{MHz}, \mathrm{DMSO}-\mathrm{d}_{6}\right) \delta \mathrm{ppm:} 14.31\left(\mathrm{CH}_{3}\right), 22.53,26.33\left(\mathrm{CH}_{2}\right), 27.56$,

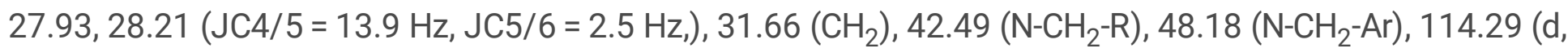
$\mathrm{J}=11.2 \mathrm{~Hz}, \mathrm{Ar}-\mathrm{C}), 127.09(\mathrm{~J}=2.5 \mathrm{~Hz}), 128.6,129.2,131.6,135.6$ (Ar-C), 163.63 (C-Se). Anal. Calcd: C, $63.32 ; \mathrm{H}, 6.99 ; \mathrm{N}, 7.77 \%$. Found: $\mathrm{C}, 60.21 ; \mathrm{H}, 6.17 ; \mathrm{N}, 6.9 \%$.

\subsection{Anticancer Studies}

Preparation of cell culture

Initially, B16F10, RGC-5, MCF-7 and Hela cells were harbored and grown under incubated environment. The cell achieving $75-80 \%$ confluency were selected for cell plating. After discarding the old medium, the cells were washed thrice using phosphate-buffer saline of $\mathrm{pH} 7.4$ then the buffer was also washed completely. Then trypsin was added in way to evenly immerse the cell thoroughly and they were incubated in $5 \% \mathrm{CO}_{2}$ for 1 minute at $310 \mathrm{~K}$. Then the cells were cautiously tapped so as to promote cell segregation which was monitored under inverted microscope. Then freshly prepared $10 \%$ Fetal Bovine Serum (FBS) was inoculated upto $5 \mathrm{~mL}$ as as to explore trypsin activity. Finally, $100 \mathrm{~mL}$ of cell media having concentration $2.5^{\star} 105$ cells per one $\mathrm{mL}$ per well was added and incubated with $5 \% \mathrm{CO}_{2}$ as internal environment at $37^{\circ} \mathrm{C}$.

\subsubsection{MTT assay}

MTT assay was accomplished as per our reported methodology [38].

\section{Results And Discussion \\ 3.1 Molecular docking}

The activities of synthesized analogues were presumed while assessing their anti-angiogenetic potential wherein the potential of each analogue to inhibit four angiogenic factors including COX-1

(Cyclooxygenase-1), EGF (human epidermal growth factor), VEGF-A (vascular endothelial growth factor A) and HIF (Hypoxia-inducible factor) was studied (structures of all shown in Fig. 1). All of four factorproteins are actively involved in the supply of oxygen and nutrients to cancer cells. The binding affinities and ligand efficiency of $\mathbf{5}$ and $\mathbf{6}$ was assessed, taking 5-Fluorouracil and sunitinib as standard reference [7]. 
The docked conformation of synthesized Se-NHCs binding to block tested oncogenic proteins were studied focusing side-chain interactions wherein short chain electrostatic interactions specially are considered.

\subsection{Docking Interactions of test Compounds with VEGFA 3.1.1 The interactions between VEGFA with Compound 6}

The docking study of 6 were also fascinating interactions to VEGFA, offering different types of binding sites. It has potential binding interaction wherein alkyl residues of arginine (Arg A:23), isoleucine (lle A:29) and leucine (leu A:32) interact with octyl chain and xylyl core; hydrogen-atom of histidine (His A:27) residues interact with benzimidazolium portion as per pictorial diagram given in Fig. 2. In view of its promising interaction, it shows very low binding energy value $(-6)$ demonstrating its higher stability of its supposed complexation to inhibition VEGFA.

\subsubsection{The interactions between VEGFA with Compound 5}

Compound $\mathbf{5}$ also showed significant interaction for VEGFA with alkyl residues of (Met A:55), (lle A:76), (Ile A:91), and (Pro A:49) of VEGFA. Moreover, its potential to interact with carbon-hydrogen bond of (Lys $A: 48$ ); and with pi-sulfur bond of (Met A:78) is also significant. It showed good to better interaction for having binding energy value -4.66 compared to -6 value of sunitinib (positive control) which provokes for its synthesis to test their In-Vitro and In-Vivo trials. The anticancer trials while inhibiting VEGFA through multilateral geometric fitting as shown in Fig. 3. As isoleucine has interaction with selenium portion; with benzilium ring of xylyl; methionine has interaction also with xylyl of benzimidazolium as well as benzimidazole portion through its sulfur residues.

\subsubsection{The interactions between VEGFA with Flourouracil (FU)}

Flourouracil was taken as positive control which is well recognized anticancer standard drugs for comparative anticancer studies [13]. Due to presence of a number of polar groups in its structural skeleton, it was found an interactive compound for its hot-spot binding with various functionalities [14] especially with oxygen-hydrogen bond of (Phe A:38), (Ser A:50) and (Asp A:34) and carbon hydrogen bond of (lle A:46) of VEGFA as shown in Fig. 4.

\subsubsection{The interactions between VEGFA with sunitinib}

Sunitinib offer its potential binding interaction with VEGFA which justifies its proven and reported potential as multi-kinase and angiogenesis inhibitor [15]. The conformational view in the pictorial diagram shows that it has binding affinity with both of non-polar and polar amino acids in peptide backbone of VEGFA as it interacts with carbon hydrogen bond of glutamic acid (Glu A:35) and aspartic acid (Asp A:11) which are polar amino acids and with the same of proline (Pro A:40), and tyrosine (Tyr A:39) which are often considered non-polar amino acids. Furthermore, it is also interactive with hydrogen of fluorine of Serine (Ser A:50) as shown in Fig. 5.

\subsection{Docking Interactions of test Compounds with COX1}




\subsubsection{The interactions between COX1 and Compound 5}

The results after the assessment of interaction potential for $\mathbf{5}$ shows recurrence of previous trend as it showed with VEGFA. It was found a better and effective analogue among Se-NHC having alkyl groups as showed binding energy value (-7.82) as compare to (-7.32) of Compound 6 which is more negative and consequently found more active anticancer as shown in Fig. 6 . And it has also been inferred that hexyl is among the most suitable ligands containing alkyl substituents. If we see it conformational diagram in the given pictorial diagram it will be justified that it has pi-sigma, alkyl-akyl and carbon-hydrogen interactions as major key ligating agents to inhibit COX1 while interacting with (Pro A:542); (Glu A:543); (Tyr A:64); and of (Ile A:43).

\subsubsection{The interactions between COX1 and Compound 6}

In the assessment of COX1 interaction for 6 , it was found that it showed its highest interaction potential to COX1 as compare to its interactions with other growth factor proteins like VEGF, EGF and HIF as shown in Fig. 7 it shows higher stability of its probable complex with COX1 on basis of its lower binding energy is lower (-7.32) than that of positive control FU (-4.92). It shows interaction while interacting with alkyl groups, pi-bond and others of (His A: 226); (Phe A:142; (Val A:145); and (Ser A:143).

\subsubsection{The interactions between COX1 and FU}

The motif of versatile activity in blocking oncogenic proteins for flourourcil is admissible in docking analysis while presenting Fig. 8 to demonstrate its binding to inhibit cyclooxygenase enzyme-1 (COX-1) wherein promising degree of binding due to its polar groups like oxygen atom and acidic hydrogen atom was noted. Polar atoms showed their electrostatic interaction especially by hydrogen bonding or carbon hydrogen bond or others with (Thr A:331); (Thr A:549); (Ser A:545); and (Ile A:137).

\subsubsection{The interactions between $\operatorname{COX} 1$ and sunitinib}

The reported interaction of sunitinib with COX1 again found promising as it was found in case of VEGFA. Its potential interaction with various amino acid residues especially with (Pro A:158); (Asp A:135); (lle $A: 46) ;(C y s$ A:42); (Gln A:161); (Gln A:44); (Glu A:465); (Arg A:469); and (Leu A:152) shows its higher affinity to the both polar and non-polar amino acids as shown in Fig. 9. In view of its interaction with amino acids of all types of polarities, it ligates through hydrogen bonding, pi-sigma-interaction, pi-pi interaction, Van der Waal interaction and others. It showed lowest binding energy value (-8.87) among all test ligands.

\subsection{Docking Interactions of test Compounds with HIF 3.3.1 The interactions between HIF and Compound 5}

HIF inhibition studies, 5 was considered a one of the most effective inhibitor showing its binding energy value (-6.34) which was very close that of positive control (sunitinib). It showed promising activity on the basis of its probable interactions like: pi-sigma, pi-alkyl, alkyl-alkyl and others. The major interacting 
amino acids were histidine, isoleucine, Phenylalanine, glutamic acid residues which were detected spatially as (Phe A:111); (His A:234); (Pro A:21); (Val A:336); (Ile A:222); (lle A:344); (Llu A:340); and (Glu A:325) as shown in Fig. 10. Its higher interaction paves a way for various types of structural changes to develop new derivative-analogues of this compound in view of its geometric fitting.

\subsubsection{The interactions between HIF and Compound 6}

Compound 6 demonstrated a binding energy value $(-5.56)$ which was also very close to the highly active anticancer positive control (sunitinib). But the value was the lowest among all other test compounds but it was higher than fluorouracil. In the given pictorial diagram its interactions like: pi-alkyl, pi-sigma, alkylalkyl and others interactions targeting residues of different amino acids like threonine, glutamic acid, phenylalanine and leucine which were spatially as (Phe A:111); (lle 322); Glu A:323); (Pro A:231); (Val A:338); and (Leu A:340) as shown in Fig. 11.

\subsubsection{The interactions between HIF and sunitinib}

Higher binding interaction testified our selection of sunitinib as positive control for this study. In case of interactional study with hypoxia inducible factor protein, it showed a binding energy value (-7.4) which extremely negative to offer greater inhibition potential. It was found that HIF interacts with various types of amino acid residues of both polar and less polar nature through hydrogen bonding and Van der Waal interaction as shown in Fig. 12 wherein it showed consistent affinity to agrinine, threonine, serine, glycine and alanine which are spatially as (Arg A:33); (Ser A:34); (Arg A:215); (Phe A:37); (Thr A: 39); (Ala A:10); (Ser A:11); and (Gly A:14).

\subsubsection{The interactions between HIF and FU}

Inspite of its proven and versatile efficiency of fluorouracil but in case of scavenging HIF protein, it was not found an effective analogue because of its higher binding energy value (-4.68) among all other test ligands. It might be due to its higher polarity which might not afford geometric fitting in non-polar environment of amino acid residues but it has, binding interaction with (Leu A:101); (Ser A:118); (GIn A:147) through hydrogen bonding, carbon hydrogen bond and its fluorine linkages shown in Fig. 13.

\subsection{Docking Interactions of test Compounds with EGF 3.4.1. The interactions between EGF with Compound 5}

Interaction of EGF with $\mathbf{5}$ was also fascinating and was better than that of $\mathbf{6}$ but it was not much closer to the that of positive control as $\mathbf{5}$ has a value (-5.08) compared to (-7.09) of sunitinib. As the both $\mathbf{5}$ and $\mathbf{6}$ have almost similar binding energy value which might be ascribed to the presence of non-polar alkyl chains attached on nitrogen atoms which show a lack of binding potential in elaborated in Fig. 14.

\subsubsection{The interactions between EGF with Compound 6}

In case of 6, all docked conformations were interactive to block epidermal growth factor-A (EGF) showing a binding energy value (-4.36) which higher than that of $\mathbf{5}$ as well as than that of two studied positive 
controls that reveals its lower stability after binding with EGF. However, it has shown multiple type of binding sites originating from interacts with benzilium of xylyl portion and from various structural appendages while targeting various amino acid residues of (Cys A:14); (Cys A:20); (Asp A: 11); (Cys A:8); (Asp A:17); and (Val A:26) as shown in Fig. 15.

\subsubsection{The Interactions between EGF with FU}

Florouracil has long been known as an active cytotoxic agent for cancer cells and this fact has been testified again in our study. In given pictorial diagram, almost all polar groups are showing pronounced interaction with different amino acids residues of EGF which include: cysteine, tyrosine, proline, aspartic acid, leucine and glycine which are spatially as (Pro A:7); (Cys A:12); (Tyr A:13); (Gly A:12); (Cys A:20); (Leu A:8); and (Asp A:1) as elaborated in Fig. 16. All amino acids are interacting through hydrogen bonding or other strong electrostatic interaction using their polar groups to associate either with electronegative nitrogen/oxygen atom or electropositive hydrogen atom. Due this reason, it has higher stability of its complex with EGF-protein.

\subsubsection{The interactions between EGF with sunitinib}

After fluorouracil, sunitinib showed lowest bindind energy value to demonstrate highest stability of its probable complex with EGF that is likely due its higher degree of interactions with multiple types of amino acid residues present in the target protein as shown in Fig. 17. Its main target amino acids are- cystiene, glycine, tyrosine, aspartic aicd, leucine and histidineas shown in Fig. 17. Its polar and non-polar groups both showed multiple types of binding interactions including van der waal, hydrogen bonding, pi-alkyl, alkyl-alkyl, pi-ionic pi-anionic, pi-sigma interactions with (Cys A:14); (Cys A:20); (Cys A:6); (Tyr A:13); (Gly $A: 18) ;($ Leu $A: 8)$; and (Asp A:11) might be due to the presence of its both polar and non-polar groups.

The overall ad summarized results of all docking outcomes are given in Table. $\mathbf{2 . 1}$ wherein comparative binding energies for all devised analogues in terms of gibbs free energy.

Table. 2.1 Comparative Binding Potential of Test Compounds 5 and $\mathbf{6}$ with Angiogenic Factors 


\begin{tabular}{|c|c|c|c|c|c|c|c|c|c|c|c|}
\hline Ligands & Run & & & & & & & & & & $\mathbf{K i}$ \\
\hline \multicolumn{12}{|c|}{ VEGF } \\
\hline 6 & 29 & -4.4 & -4.39 & -4.28 & -4.24 & -4 & -3.88 & -3.76 & -3.75 & -3.75 & $593.30 \mathrm{uM}$ \\
\hline 5 & 97 & -5.3 & -5.08 & -5.01 & -4.97 & -4.93 & -4.87 & -4.74 & -4.73 & -4.66 & 130.58 uM \\
\hline sunitinib & 76 & -6.71 & -6.56 & -6.48 & -6.45 & -6.44 & -6.05 & -6.03 & -6 & -6 & $12.12 \mathrm{uM}$ \\
\hline $5 F U$ & 3 & -4.97 & -4.24 & -4.05 & -4 & -3.93 & -3.86 & & & & 229.15 uM \\
\hline \multicolumn{12}{|c|}{ EGF } \\
\hline 6 & 66 & -6.18 & -5.42 & -4.92 & -4.88 & -4.58 & -4.48 & -4.39 & -4.37 & -4.36 & $29.74 \mathrm{uM}$ \\
\hline 5 & 3 & -5.87 & -5.77 & -5.64 & -5.57 & -5.43 & -5.38 & -5.09 & -5.08 & -4.96 & $49.83 \mathrm{uM}$ \\
\hline $5 F U$ & 36 & -4.97 & -4.93 & -4.71 & & & & & & & 227.34 uM \\
\hline sunitinib & 43 & -8.11 & -7.98 & -7.7 & -7.44 & -7.42 & -7.31 & -7.1 & -7.09 & -7.06 & $1.14 \mathrm{uM}$ \\
\hline \multicolumn{12}{|c|}{ Cox1 } \\
\hline 6 & 96 & -9.65 & -9.03 & -8.36 & -8.11 & -8.1 & -7.98 & -7.61 & -7.45 & -7.32 & $84.46 \mathrm{nM}$ \\
\hline 5 & 80 & -9.16 & -8.6 & -8.54 & -8.37 & -8.35 & -8.2 & -8.18 & -7.99 & -7.82 & $192.44 \mathrm{nM}$ \\
\hline $5 F U$ & 2 & -5.09 & -5.04 & -5.01 & -5 & -4.97 & -4.95 & -4.95 & -4.92 & -4.92 & 187.11 uM \\
\hline sunitinib & 85 & -10.3 & -9.84 & -9.71 & -9.28 & -9.22 & -9.03 & -8.93 & -8.88 & -8.87 & $28.04 \mathrm{nM}$ \\
\hline \multicolumn{12}{|c|}{ Hif } \\
\hline 6 & 41 & -6.74 & -6.54 & -6.47 & -6.17 & -6.05 & -5.9 & -5.81 & -5.64 & -5.56 & $11.40 \mathrm{uM}$ \\
\hline 5 & 57 & -7.64 & -6.83 & -6.63 & -6.49 & -6.49 & -6.47 & -6.45 & -6.38 & -6.34 & $2.49 u M$ \\
\hline $5 F U$ & 3 & -5.26 & -5.17 & -5 & -4.92 & -4.84 & -4.79 & -4.76 & -4.76 & -4.68 & 138.96 uM \\
\hline sunitinib & 85 & -8.21 & -8.08 & -7.92 & -7.84 & -7.76 & -7.74 & -7.72 & -7.59 & -7.4 & $964.34 \mathrm{nM}$ \\
\hline
\end{tabular}

\subsection{Synthesis and Preliminary Cytotoxic Confirmations}

In this study, preliminary synthetic confirmation were made on the basis of solubility, melting points and their physical states [38]. In this context, it was noted that selenium adducts appeared as light-brown sticky mass and their respective benzimidazolium salt $\mathbf{2}$ and $\mathbf{3}$ appeared in form of creamy white-flakes. Bis-benzimidazolium salts were soluble in hot distilled water and the adducts, on the other hand, were soluble in alkanols and DMSO. Moreover, the melting points of the adducts were lower than that of their respective salts. In this way, synthesized analogues were preliminary assumed successful in view of the concordance of their properties with reported literature [8].

\subsubsection{Spectroscopic Confirmations}

The confirmation of successful synthesis as per their proposed structures, ${ }^{1} \mathrm{H}$ and ${ }^{13} \mathrm{C}$-NMR along with FTIR spectroscopic studies were accomplished as per the concordance of reported literature. The change in FT-IR spectra of benzimidazolium salts (2\&4) and their corresponding Se-NHC adducts (5 \&6) in 1100$1600 \mathrm{~cm}^{-1}$ region was observed. The emergence of distinct peaks in case of salts and their suppression in case of selenium adducts in region $1750-1550 \mathrm{~cm}^{-1}$ were clearly observed. Furthermore, another distinct four-fingers like pattern of peaks were observed in region $1500-1300 \mathrm{~cm}^{-1}$ in case of selenium adducts as a sign to confirm their successful synthesis. In ${ }^{1} \mathrm{H}-\mathrm{NMR}$ spectra, appearance of singlet peak in $\delta 7.5-\delta 10$ range confirmed the synthesis 2 and 4.And these disappearance of acidic proton peak confirmed the synthesis of $\mathbf{5}$ and $\mathbf{6}$. Moreover, ${ }^{13} \mathrm{C}$ NMR spectra of salts ( $\mathbf{2}$ and $\left.\mathbf{4}\right)$ further verified the successful synthesis of Se-NHC adducts wherein chemical shift value of NCN carbon was changed from region (142-148 $\delta \mathrm{ppm}$ ) in azolium salts as compared to selenium adducts ( 5 and 6 ) which appeared in the range (165-168 $\delta \mathrm{ppm}$ )as per reported literature [34,43-45].The successful synthesis of $\mathbf{1}$ and $\mathbf{3}$ was confirmed on ${ }^{13} \mathrm{C}$-NMR on account of appearance new peaks emerged in $\delta 49$ - $\delta 56$ range $[8,16,17]$. 


\subsubsection{In-Vitro Anticancer of Synthesized azolium salts and their respective adducts}

After molecular docking analysis four cancer cell lines namely: murine melanoma cancer cell line (B16F10), rat retinal ganglion cancer cell line (1-8RGC5), cervical cancer cell line (HeLa) and breast cancer cell line (MCF7-1) were selected for in vitro anticancer study.

\subsection{2 (a) In-Vitro Anticancer Activities of the test Compounds Against B16F10}

B16F10 cell-line was selected for its reported use as a model in assessing anti-metastasis potential of developed anti-cancer agents (drugs). Because in assessing the potential of any drug, B16F10 cells can be considered as a good determinant to assess the activity of anticancer agent especially in context to skin cancers. Cell growth was markedly inhibited after exposure to the test compounds in a dosedependent manner. It was also showed that numerous morphological changes occurred in cells treated with test compounds. Apoptosis was confirmed by the presence of apoptotic bodies and nuclear condensation. The control, cultured cells without test compounds and cultured with fluorouracil has been shown in each elaboration. However, fluorouracil (positive control) exhibited significant apoptotic activity but some test compounds showed better activity than that. The activity of $\mathbf{2}$ and $\mathbf{5}$ demonstrate that tumor cells which have an intrinsic tumorigenic potential in the control samples has offered significant cytotoxic effect in their respective sample snips in the Fig. 4.46.

It can be considered an extension of study of Haque et. al., 2013 who synthesized 1,3-bis(3ethylbenzimidazolium-1-ylmethyl)benzenebis (hexafluorophosphate) A-1 and 1,3-bis(3butylbenzimidazolium-1-ylmethyl)benzene bis(hexafluorophosphate) A-2 as well as their respective silver complexes 1,3-bis(3-ethylbenzimidazolium-1-ylmethyl)benzene disilver(I) bis(hexafluorophosphate) A-3 and 1,3-bis(3-butylbenzimidazolium-1-ylmethyl)benzene disilver(I) bis(hexafluorophosphate) A-4 respectively for anticancer applications taking fluorouracil as positive control but showed $\mathrm{IC}_{50}$ values of 8.7 and $19.4 \mathrm{mM}$ for $\mathbf{A}-\mathbf{1}$ and $\mathbf{A}-2$; and $\mathbf{0 . 2} \mathrm{mM}$ and $1.3 \mathrm{mM}$ for $\mathbf{A}-\mathbf{3}$ and $\mathbf{A}-\mathbf{4}$ respectively and $5 \mathrm{mM}$ for flourouracil against HCT 116 cancer cell-line. The good to excellent activity was gained much importance because of inherent toxicity of silver on human body [18]. The present study as aimed at designing and synthesizing bisbenzimidazolium salts and their corresponding selenium-adducts which are

biocompatible for human beings. Among these synthetic analogues $\mathbf{2}$ and $\mathbf{5}$, however, showed higher IC ${ }^{50}$ values (32 $\mathrm{mM})$ and $(101 \mathrm{mM})$ respectively and no noticeable increase with increase in dosage as shown in Fig. 19 but their release likely to have biodegradability and biocompatibility.

In case of B16F10, compound $\mathbf{6}$ was found an active cytotoxic agent but not 4, it showed IC ${ }^{50}$ value of $7.17 \mathrm{mM}$ as compare to $32.25 \mathrm{mM}$ that of $\mathbf{5}$, however, the trend demonstrated by molecular docking almost reciprocal. But the dosages dependence shoed promising increase in activity with increase in concentration especially in case of 6 as shown in Fig. 4.21.

\subsection{2 (b) Anticancer activity against 1-8RGC5}


To better assess the anticancer activity of the test compounds, multiple cancer cell lines were selected wherein second-one was rat ganglion cancer cell-line (1-8RGS5) which is often considered as a representative cell-line to assess optic nerve carcinomas. In case of compound $\mathbf{2}$ and $\mathbf{5}$ both showed excellent activity in comparison to standard 5-flourouracil wherein bisbenzimidazolium salt 2 showed $I \mathrm{I}^{50}$ value $(16.1 \mathrm{mM})$ almost equal to that of standard and selenium adduct two times higher than that of the same $(8.2 \mathrm{mM})$ compared to $(16.5 \mathrm{mM})$ of standard as shown in Fig. 22 . This study recurrently justifies the higher cytotoxicity of selenium adducts to cancer-cells than that of their respective azolium salts.

Moreover, it was explored in our docking analysis that $\mathbf{5}$ has consistent affinity to interact with proline and methionine which is not attributed to 2 because of its ionic nature which might be ascribed to higher bioavailability of 5. But in case of 4 and $\mathbf{6}$ the both were found cytotoxic to 1-8RGC5 cell-line but the previous trend didn't survive because of the higher activity of bisbenzimidazolium salt 4 instead of selenium adduct 6 was explored as shown in Fig. 23 which might attributed to stronger ionic interaction of $\mathbf{4}$ with polar functionalities of oncogenic proteins.

\subsection{2 (c) In-Vitro Anticancer Activities Against HeLa}

The photomicrograph of the HeLa cells (treated with $\mathbf{5}$ in Fig. 24) shows much clear membrane blebbing and nuclear condensation as compare to the cancer cells treated with 5 -fluorouracil. But 5 shows its activity at higher $\mathrm{IC}^{50}$ value $(17.48 \mu \mathrm{M})$ compared to that of $(4.9 \mu \mathrm{M})$ for 5 -flourouracil. It infers that $\mathbf{5}$ is not so active against HeLa cell-line that might be due to some sort of hindrance in its bioavailability to target oncogenic functions.

\subsection{2 (d) Cytotoxicity of test compounds against MCF7-1}

In view of emerging trend of human breast carcinoma (MCF7-1) incidence, the study was also aimed to explore cytotoxicities of test compounds against MCF7-1 cell-line also. In case of 5, promising cytotoxicity with $\mathrm{IC}^{50}$ value $(7.22 \mu \mathrm{M})$ approximately two times the standard 5-flourouracil with $\mathrm{IC}^{50}$ value $(11 \mu \mathrm{M})$ was explored. On the other hand, its respective bisbenzimidazolium salt 2 showed three times lower cytotoxic potential with $\mathrm{IC}^{50}$ value $(38.37 \mu \mathrm{M})$ as found as compare to the same as shown in Fig. 25.

In the whole of study, the activity of compound $\mathbf{4}$ and $\mathbf{6}$ against MCF7-1 cell-line was the most important highlight in view of exceptionally higher cytotoxicity than that of the standard (5-flourouracil). Compound 4 showed more than three time with $I C^{50}$ value $(3.58 \mu \mathrm{M})$ and 6 demonstrated IC ${ }^{50}$ value $(6.14 \mu \mathrm{M})$ which is two times than that of 5 -flourouracil having $\mathrm{IC}^{50}$ value $(11 \mu \mathrm{M})$ with, seemingly, apoptotic pattern of cell-death as shown in Fig. 26. In this highlight, it was surprisingly found that both benzimidazolium salt 4 being its ionic nature and its corresponding selenium adduct 6 showed higher cytotoxic potential.

\section{Conclusion}


After designing of selenium- $\mathrm{N}$-Heterocyclic carbene adducts for anticancer activities by molecular docking approach, it was found that $\mathbf{5}$ and $\mathbf{6}$ both offer potential binding to oncogenic COX 1 ; and $\mathbf{5}$ shows binding to HIF. So both of selenium adducts were successfully synthesized by In-Situ approach and consequently their successful confirmation along with their benzimidazolium salts by FT-IR and NMR spectroscopy. When they subjected to In-Vitro anticancer activities using four cancer cell line including: murine melanoma cancer cell line (B16F10), rat retinal ganglion cancer cell line (1-8RGC5), cervical cancer cell line (HeLa) and breast cancer cell line (MCF7-1) in comparison to standard 5flourouracil. It was found that azolium salts $\mathbf{2}$ showed equivalent to that of the standard; and it adduct $\mathbf{5}$ showed two times to that of the same. On the other hand, Se-adduct 6 showed almost equivalent the standard but its azolium salt showed two times the activity of standard in case of 1-8RGC5. But in case of MCF7-1both Se-adduct 6 and its azolium salt 4 showed activity higher than the that of standard so it is to conclude that the studied Se-adducts and their respective azolium salts both are biologically active compounds and they are needed to explored biologically by futher studies.

\section{Declarations}

\section{Acknowledgments}

The authors are grateful to Higher Education Commission (HEC) of Pakistan for fund provision under National Research Programme for Universities (Grant\# NRPU-8396 \& NRPU-8198. They are also very much obliged to Mohamed B. Khadeer Ahamed of EMAN Research and Testing Laboratory, School of Pharmaceutical Sciences of Universiti Sains Malaysia, 11800 USM, Penang, Malaysia for their technical support and expert opinion.

\section{Conflict of Interest}

The authors declare that they have no conflict of interest.

\section{References}

1. Schrauzer, G. and D. White, Selenium in human nutrition: dietary intakes and effects of supplementation. Bioinorganic chemistry, 1978. 8(4): p. 303-318.

2. Flores Villavicencio, L.L., et al., Human lung cancer cell line A-549 ATCC is differentially affected by supranutritional organic and inorganic selenium. Bioinorganic chemistry and applications, 2014. 2014.

3. Bruening, C.A., et al., m-Trifluoromethyl-diphenyl diselenide, a multi-target selenium compound, prevented mechanical allodynia and depressive-like behavior in a mouse comorbid pain and depression model. Progress in Neuro-Psychopharmacology and Biological Psychiatry, 2015. 63: p. 35-46. 
4. Yang, Y., et al., The anticancer effects of sodium selenite and selenomethionine on human colorectal carcinoma cell lines in nude mice. Oncology Research Featuring Preclinical and Clinical Cancer Therapeutics, 2009. 18(1): p. 1-8.

5. Ingold, I., et al., Selenium utilization by GPX4 is required to prevent hydroperoxide-induced ferroptosis. Cell, 2018. 172(3): p. 409-422. e21.

6. Yamaguchi, T., et al., Ebselen in acute ischemic stroke: a placebo-controlled, double-blind clinical trial. Stroke, 1998. 29(1): p. 12-17.

7. Kamal, A., et al., Green Synthesis of Selenium-N-Heterocyclic Carbene Compounds: Evaluation of Antimicrobial and Anticancer Potential. Bioorganic chemistry, 2019: p. 103042.

8. Iqbal, M.A., et al., Green synthesis of mono-and di-selenium-N-heterocyclic carbene adducts: Characterizations, crystal structures and pro-apoptotic activities against human colorectal cancer. Journal of Organometallic Chemistry, 2016. 801: p. 130-138.

9. Steiner, G., et al., Heteroditopic Imino N-Heterocyclic Carbenes and Their Sulfur, Selenium, and Tungsten Tetracarbonyl Derivatives. European journal of inorganic chemistry, 2005. 2005(7): p. 13251333.

10. Kamal, A., et al., Green synthesis of selenium-N-heterocyclic carbene compounds: Evaluation of antimicrobial and anticancer potential. Bioorganic chemistry, 2019. 90: p. 103042.

11. Atif, M., et al., Synthesis, Structure, and Anticancer Activity of Symmetrical and Non-symmetrical Silver (I)-N-Heterocyclic Carbene Complexes. Applied Biochemistry and Biotechnology, 2020: p. 1-19.

13. Swamy, P.G., et al., Synthesis, anticancer, and molecular docking studies of pyranone derivatives. Medicinal Chemistry Research, 2013. 22(10): p. 4909-4919.

14. Dar, A.M., et al., Steroidal imidazoles: Synthesis, characterization, molecular docking studies with DNA and in vitro cytotoxicity. Medicinal Chemistry Research, 2017. 26(2): p. 372-383.

15. Gupta, R. and M.L. Maitland, Sunitinib, hypertension, and heart failure: a model for kinase inhibitormediated cardiotoxicity. Current hypertension reports, 2011. 13(6): p. 430-435.

16. Iqbal, M.A., et al., Potential of silver against human colon cancer:(synthesis, characterization and crystal structures of xylyl (Ortho, meta, \& Para) linked bis-benzimidazolium salts and Ag (I)-NHC complexes: In vitroanticancer studies). Chemistry Central Journal, 2013. 7(1): p. 27.

17. Iqbal, M.A., et al., Synthesis and anticancer activity of para-xylyl linked bis-benzimidazolium salts and respective Ag (I) N-heterocyclic carbene complexes. Medicinal Chemistry Research, 2013. 22(5): $p$. 2455-2466. 
18. Haque, R.A., et al., Binuclear meta-xylyl-linked Ag (I)-N-heterocyclic carbene complexes of Nalkyl/aryl-alkyl-substituted bis-benzimidazolium salts: synthesis, crystal structures and in vitro anticancer studies. Applied Organometallic Chemistry, 2013. 27(4): p. 214-223.

\section{Figures}

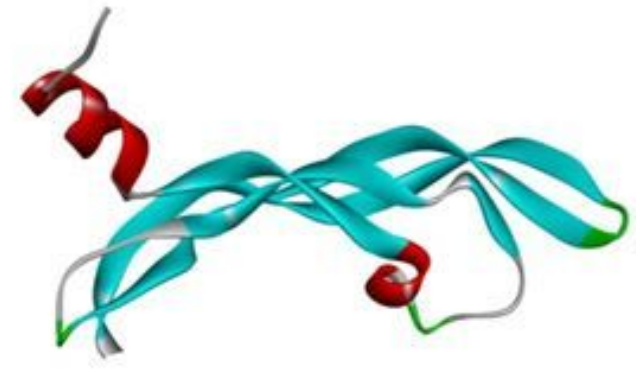

A

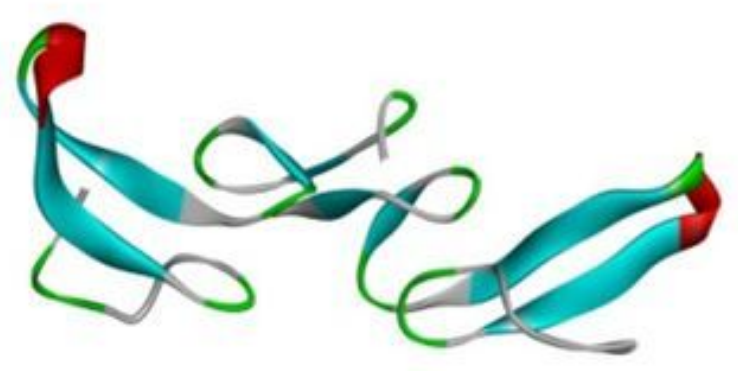

$\mathrm{C}$

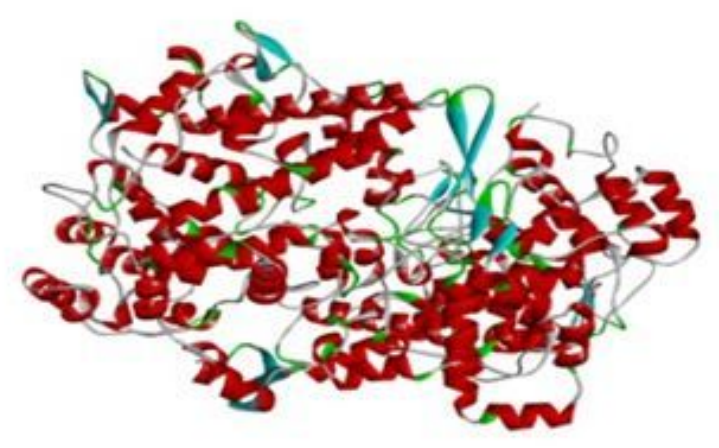

B

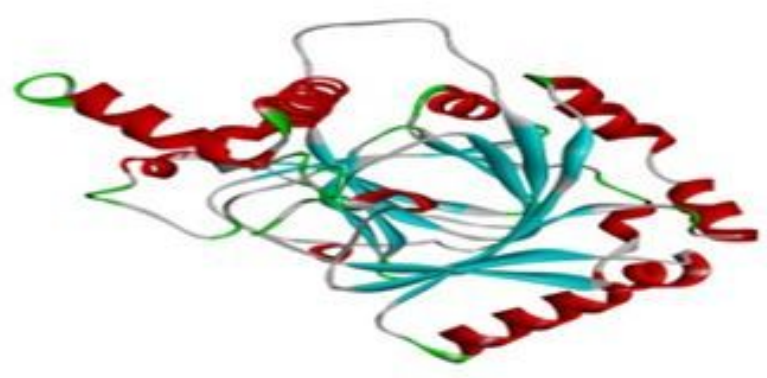

D

Figure 1

A: VEGFA protein from RCSB protein data bank (4KZN), B: COX1 protein from RCSB protein data bank (1EQH), C: EGF protein from RCSB protein data bank (1JL9), D: HIF protein from RCSB protein data bank (1YCI). 

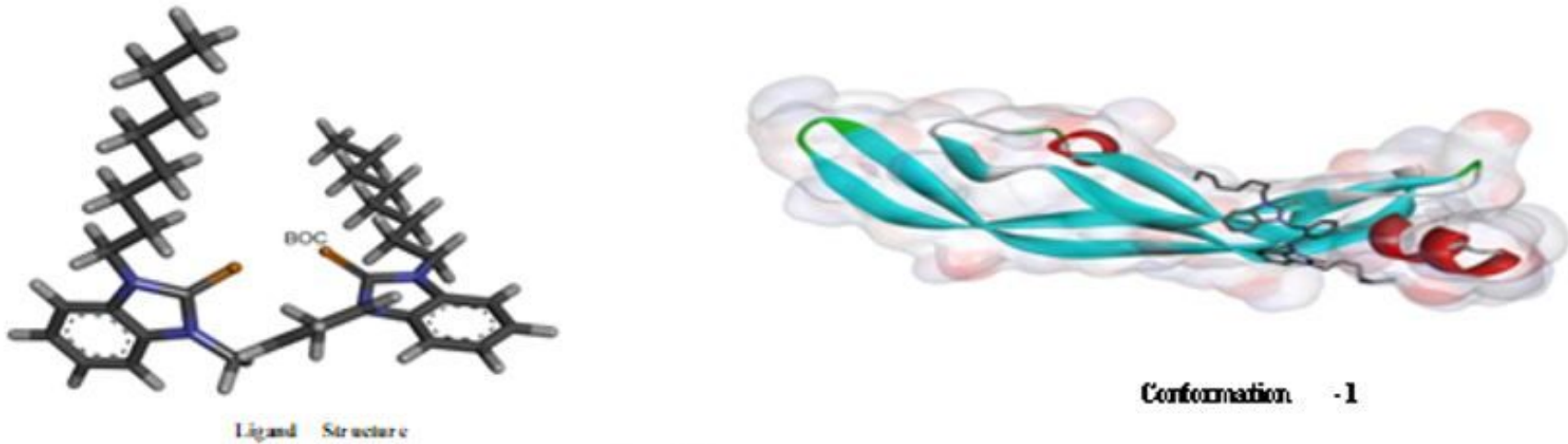

Confoumation -1
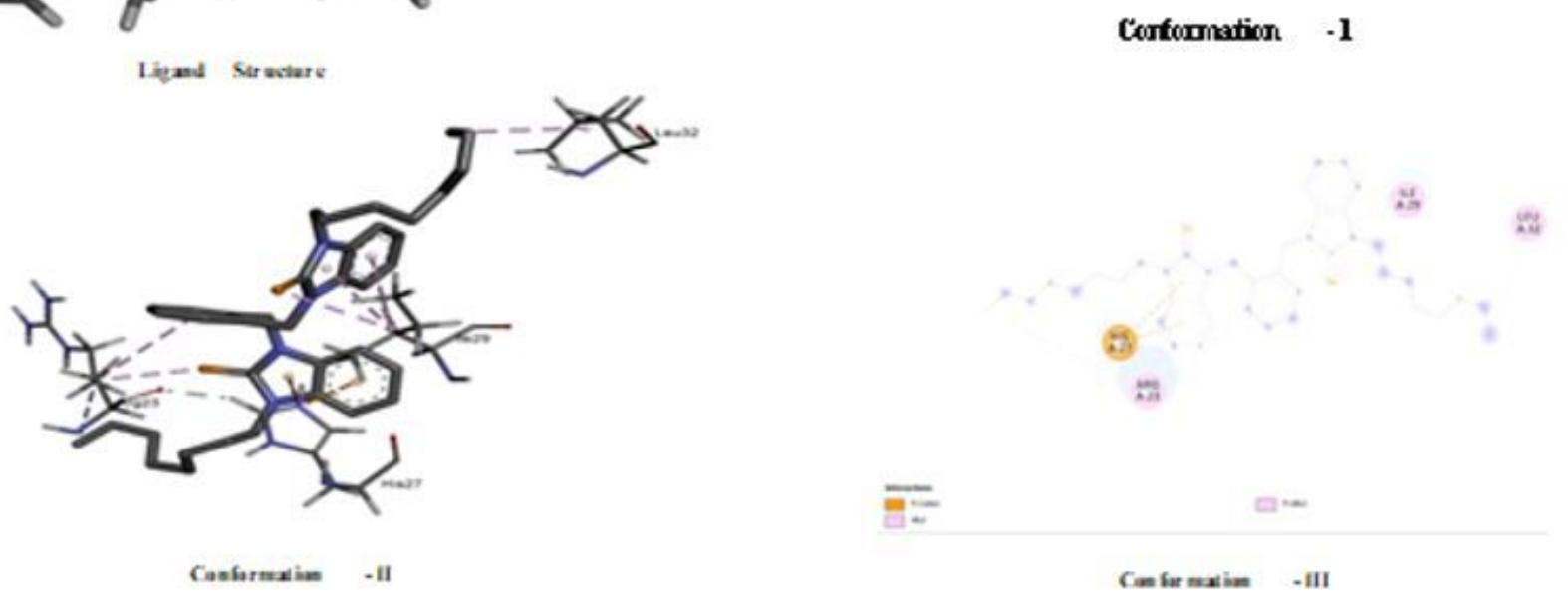

Figure 2

Interactions between VEGFA with Compound 6 


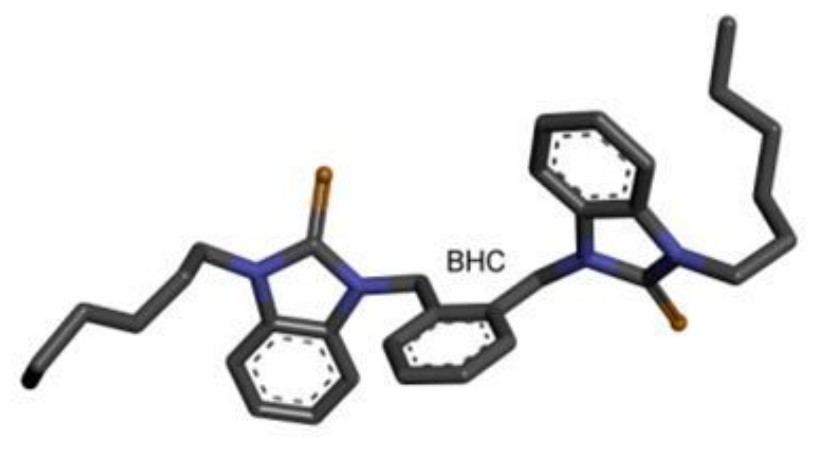

Ligand Structure

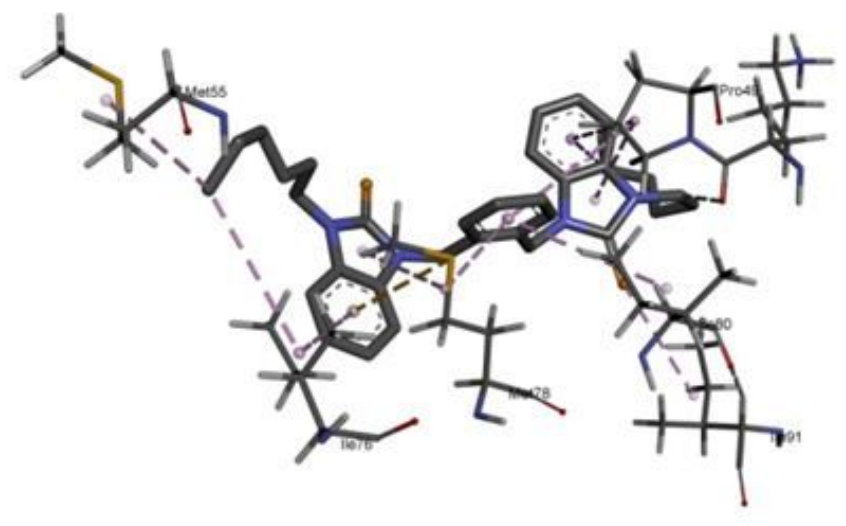

Conformation-1I

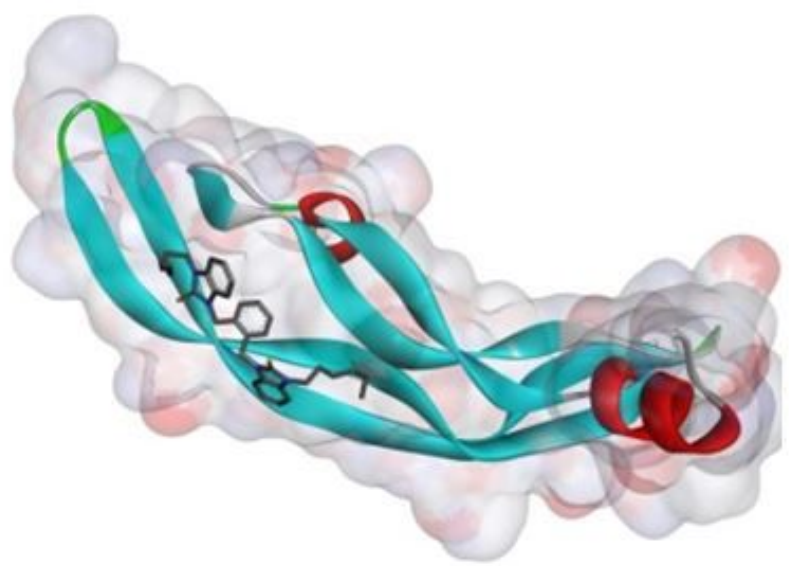

Conformation-1

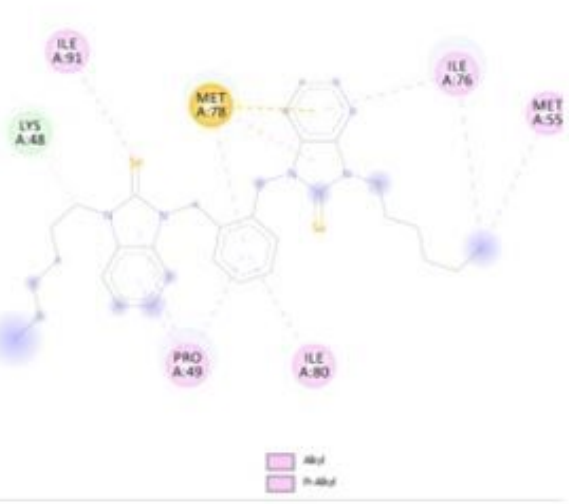

Conformation-1II

Figure 3

Interactions between VEGFA with Compound 5 


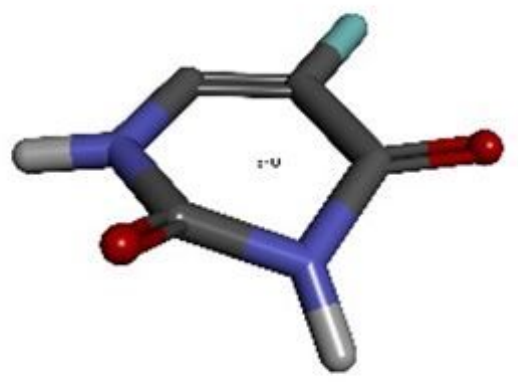

Ligand Structure

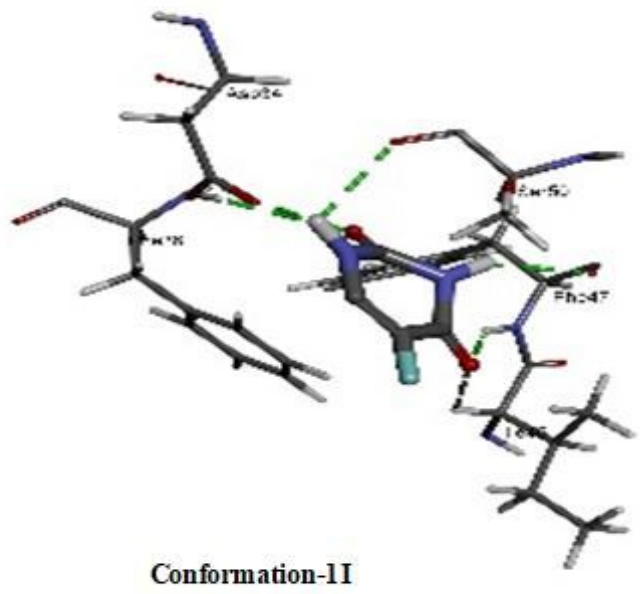

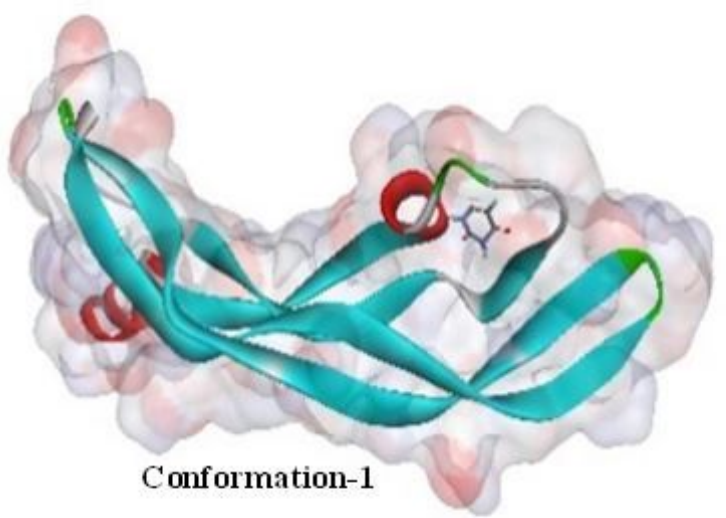

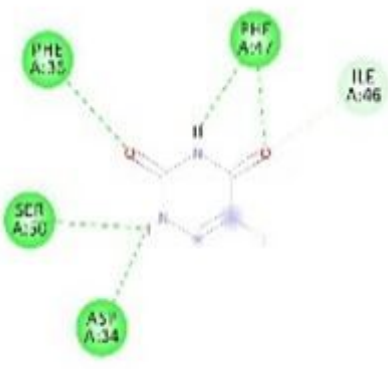

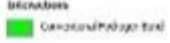

$\square$ cianominnod

Conformation-1II

Figure 4

Interactions between VEGFA with Flourouracil (FU) 


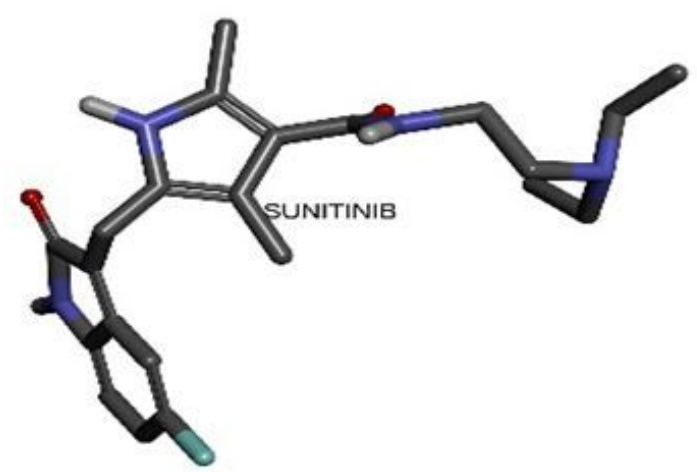

Ligand Structure

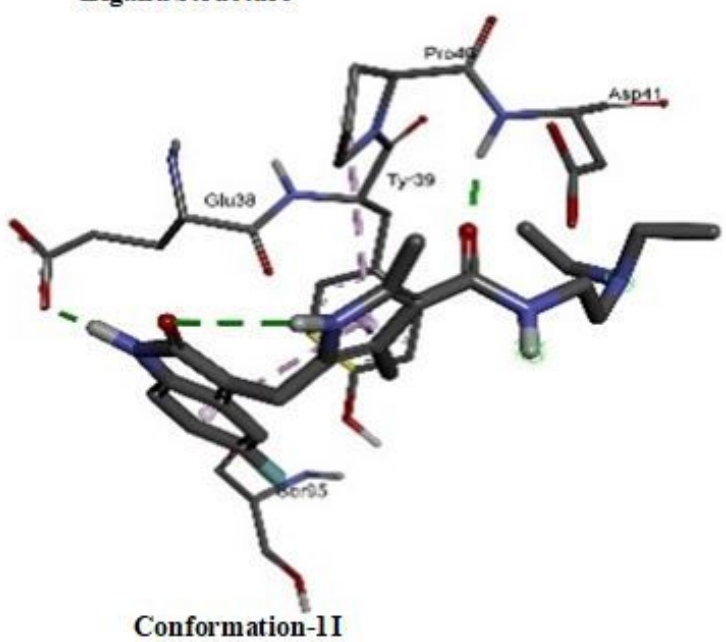

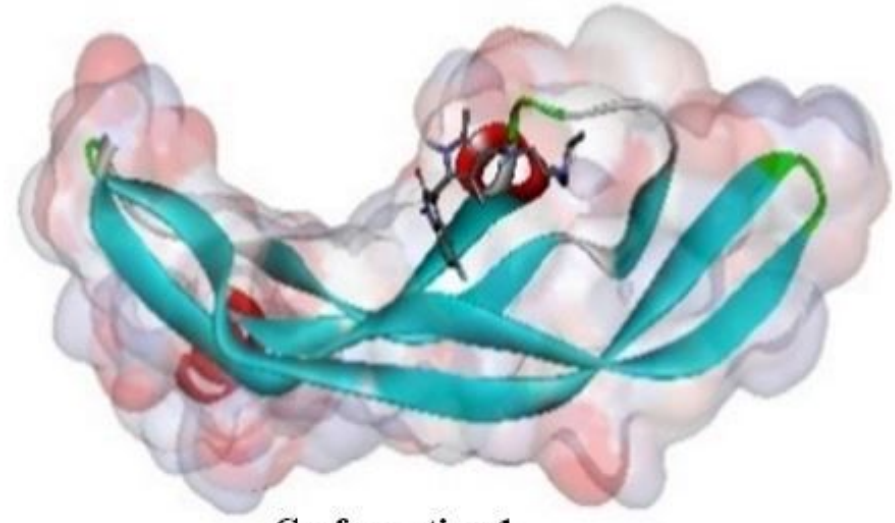

Conformation-1

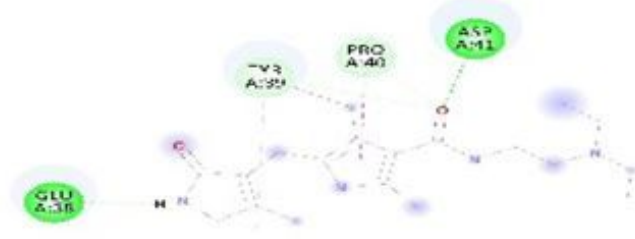

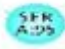

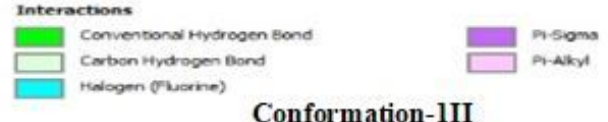

Figure 5

Interactions between VEGFA with sunitinib 

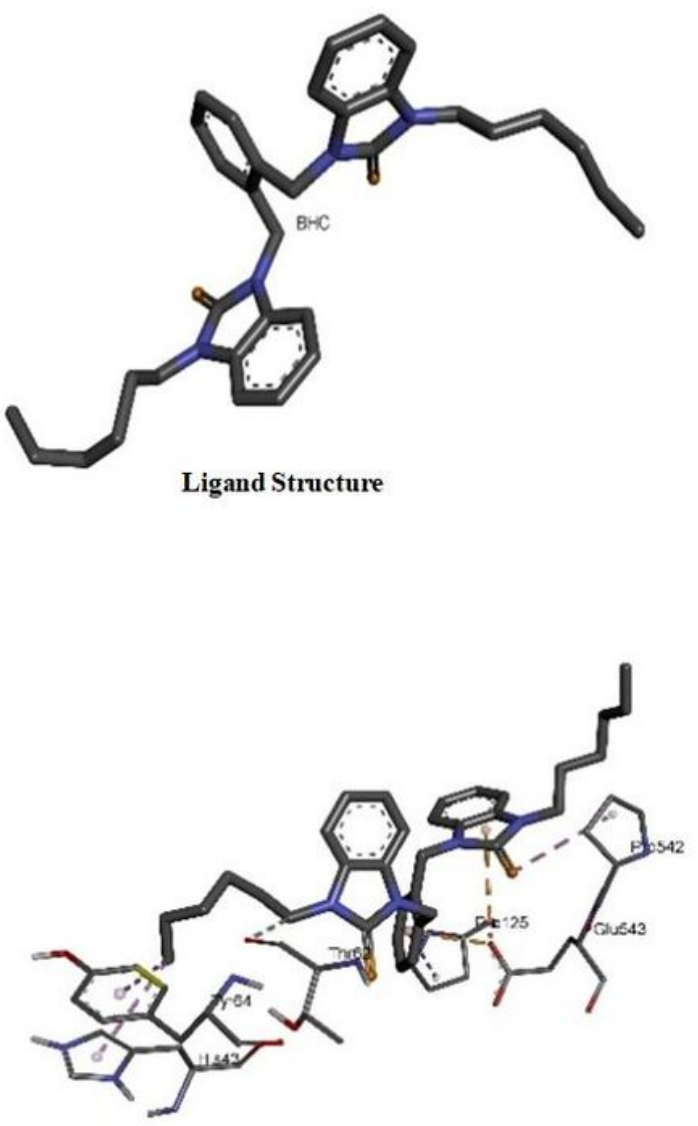

Conformation-1I

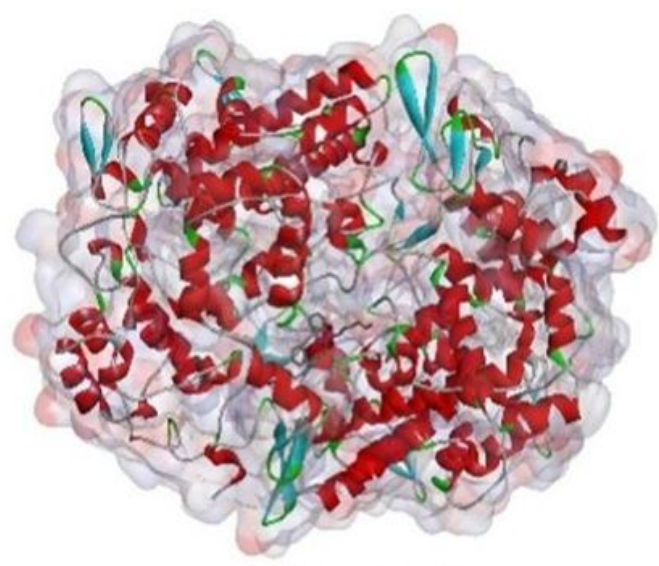

Conformation-1

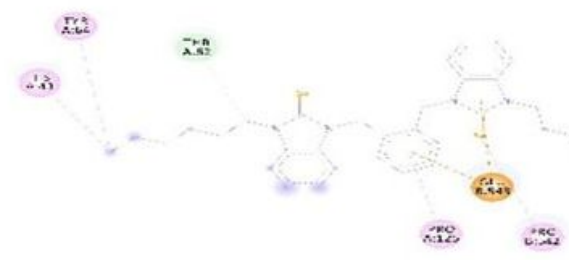

Interactions
$\square$ Carbon mydrogen Bond
Conformation-1II

Figure 6

Interactions between COX 1 and Compound 5 


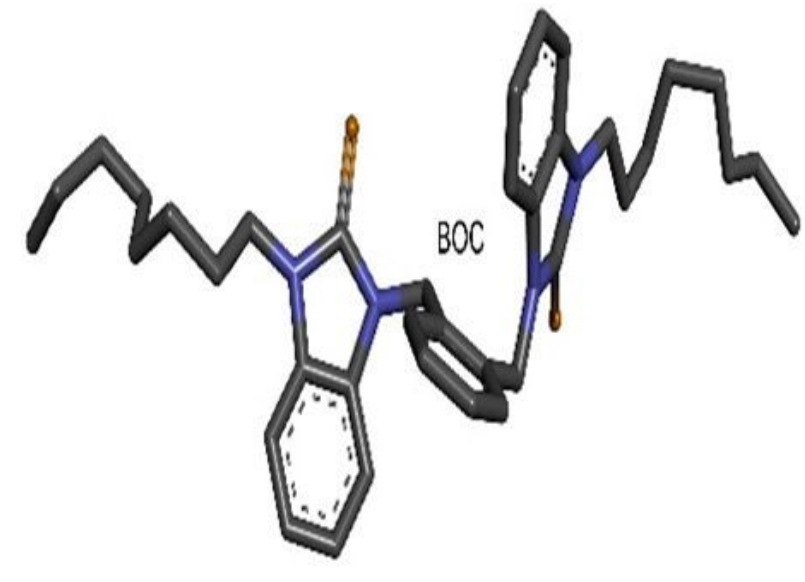

Ligand Structure

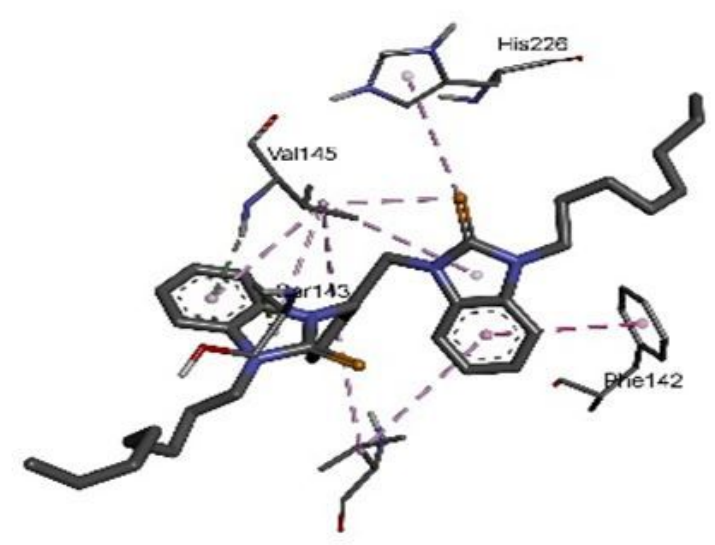

Conformation-1I

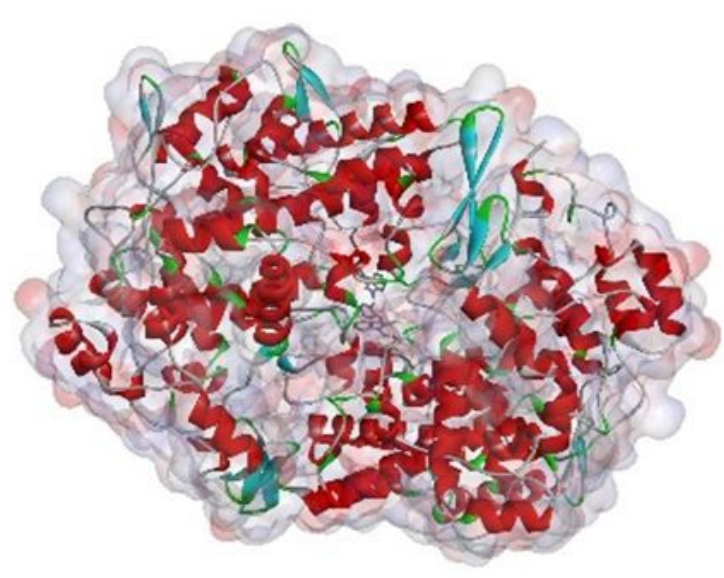

Conformation-1
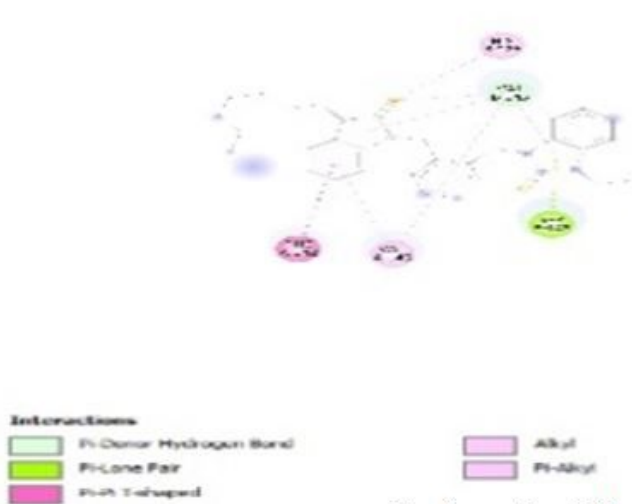

Conformation-1II

Figure 7

Interactions between COX1 and Compound 6 


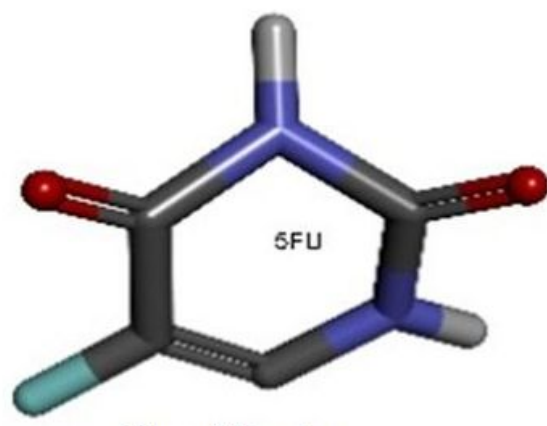

Ligand Structure

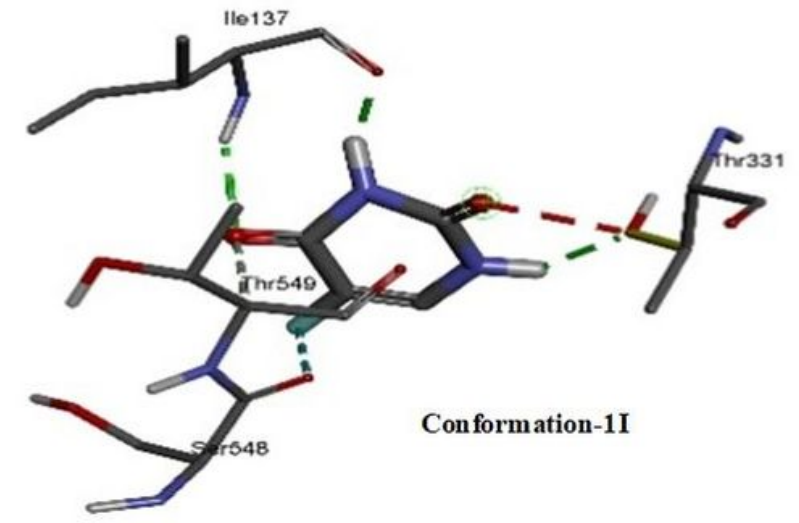

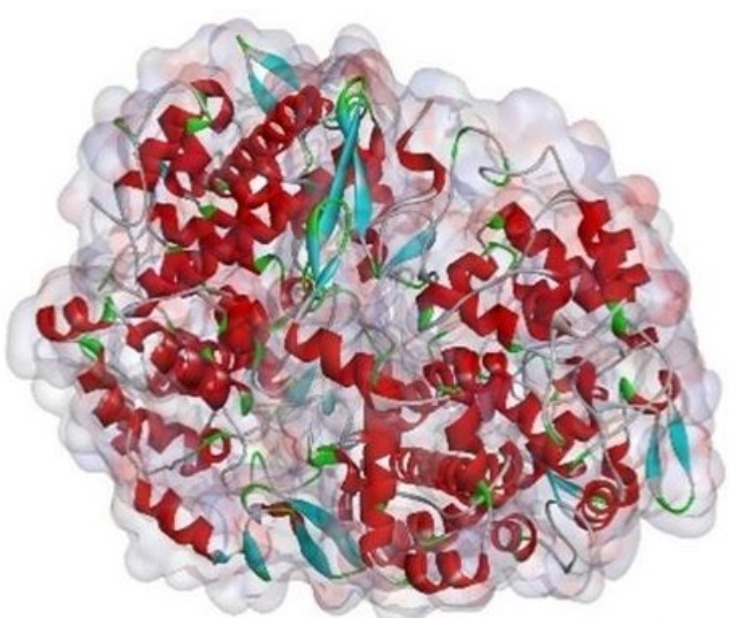

Conformation-1

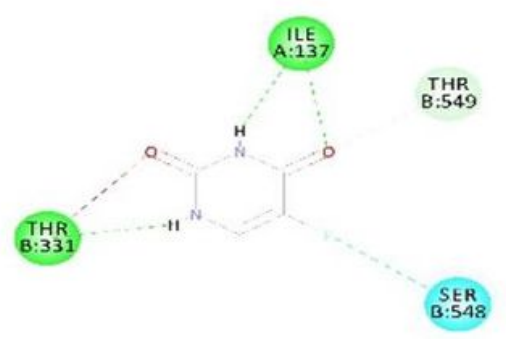

Interactions

Conventons Hirdrogen tiond

Curbon Hydrogen tond

$\square$ Hologen Fluonne)

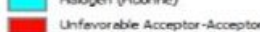

Conformation-1II

Figure 8

Interactions between COX1 and FU 

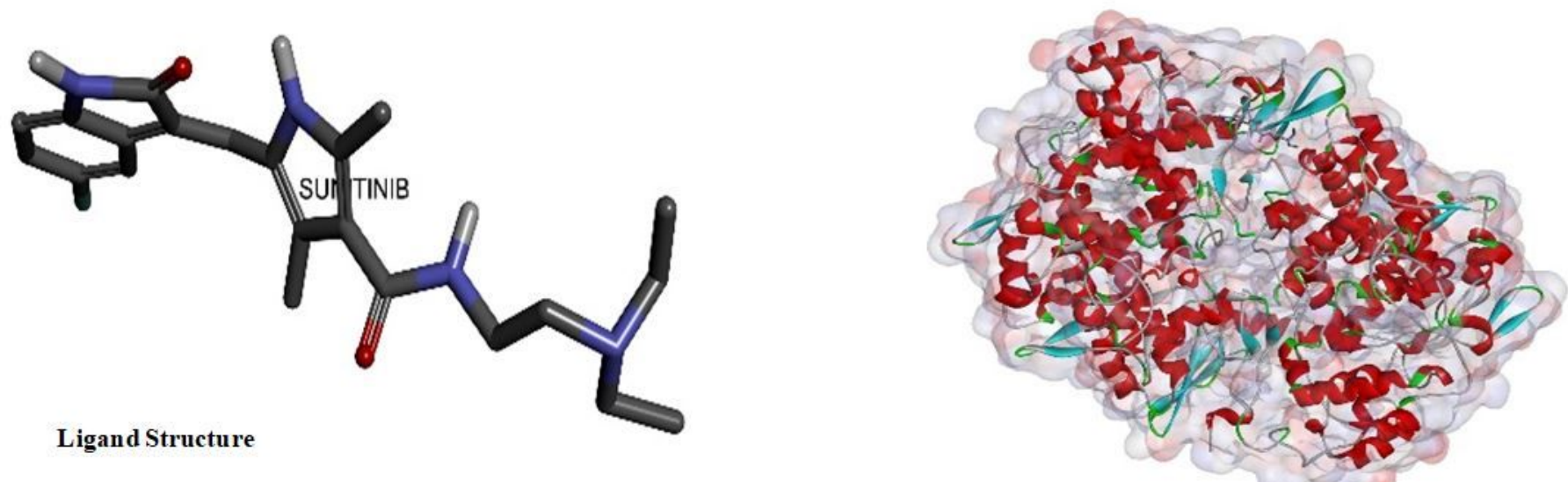

Conformation-1
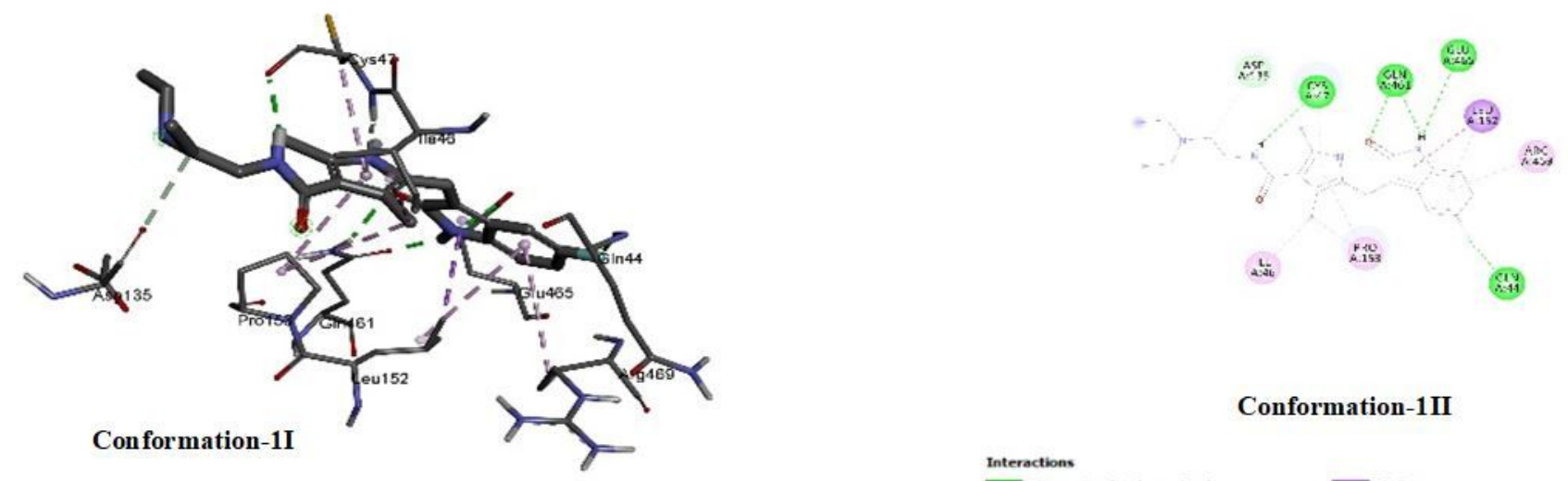

Conformation-1II

Interactions

D Conversonal ifydroper Bond

Carbon Hydrogen Bond

Pionor Hydroperi Bond

Pi-Signo
$\square$ Alkyl
$\square$ Pi-Alkyl

Figure 9

Interactions between COX1 and sunitinib 

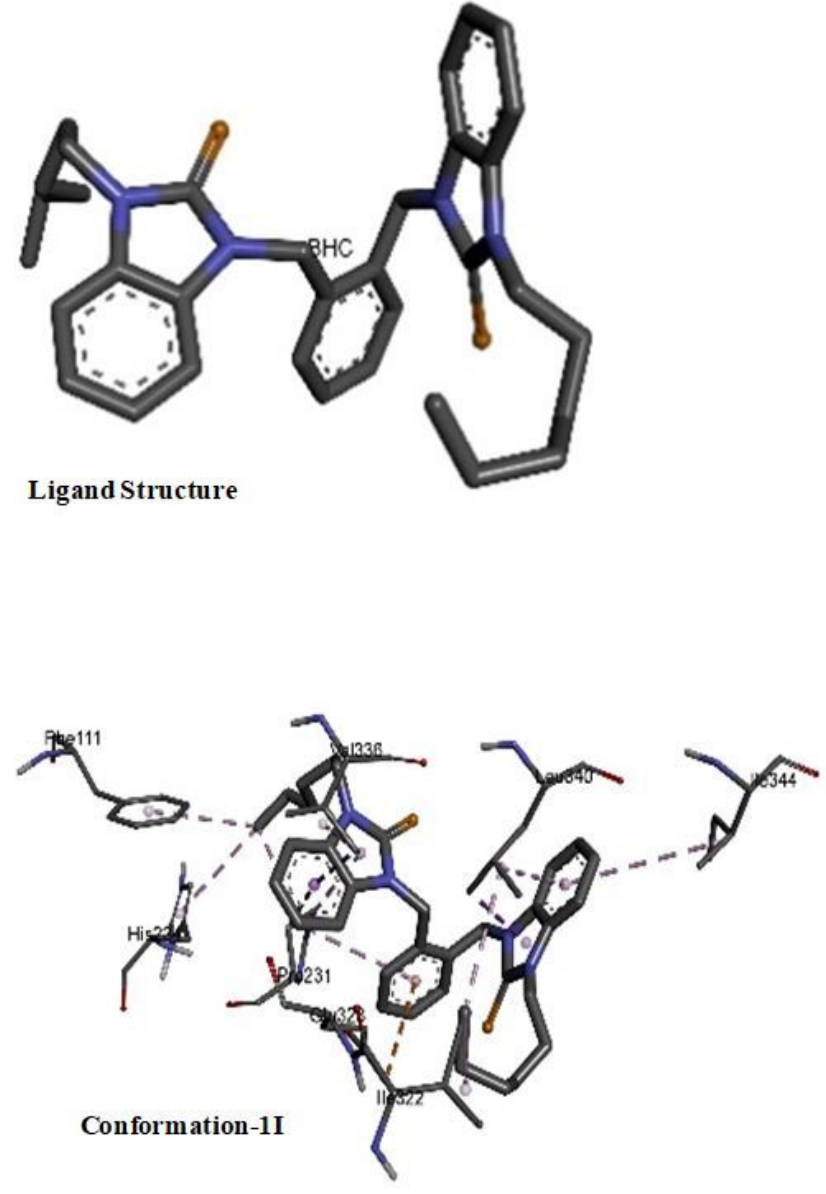

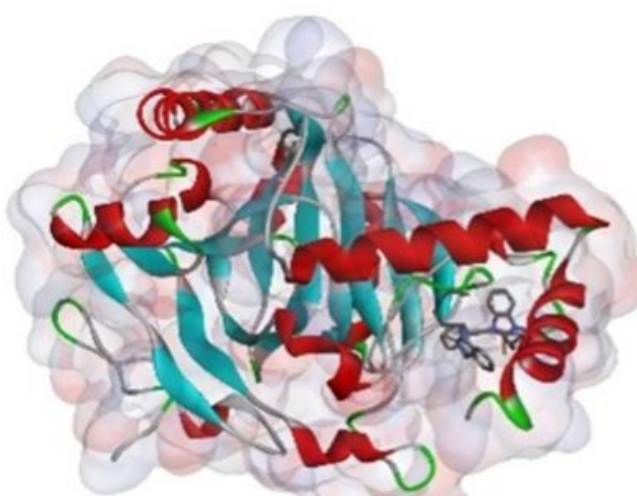

Conformation-1

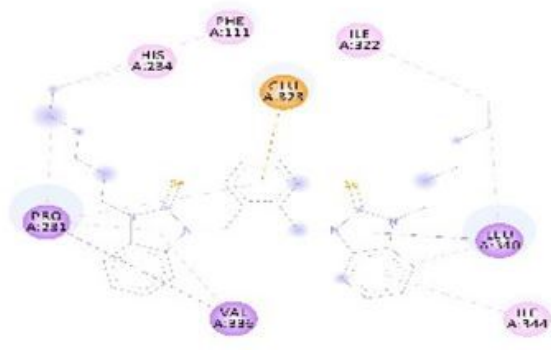

Conformation-1II

Interactions D. Arion
Disoms $\square$ Akyt

Figure 10

Interactions between HIF and Compound 5 


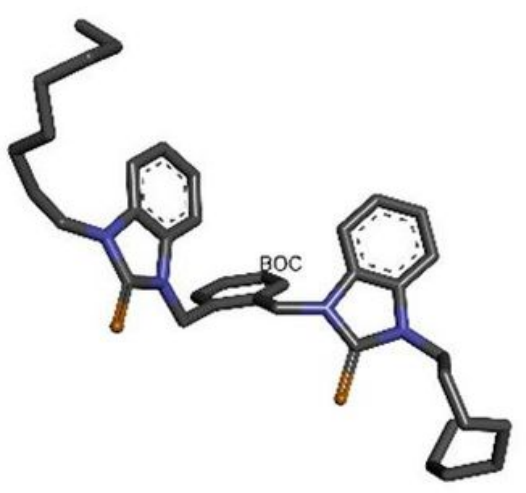

Ligand Structure

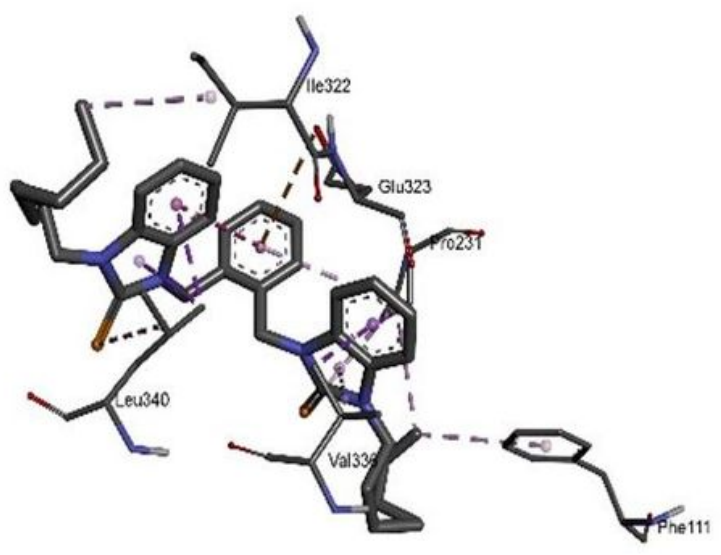

Conformation-1I

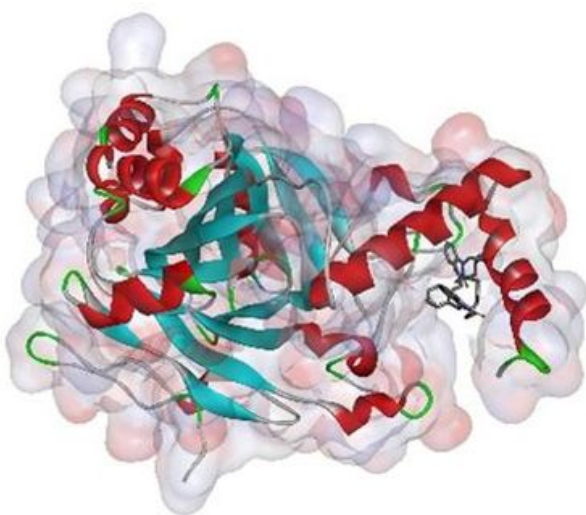

Conformation-1

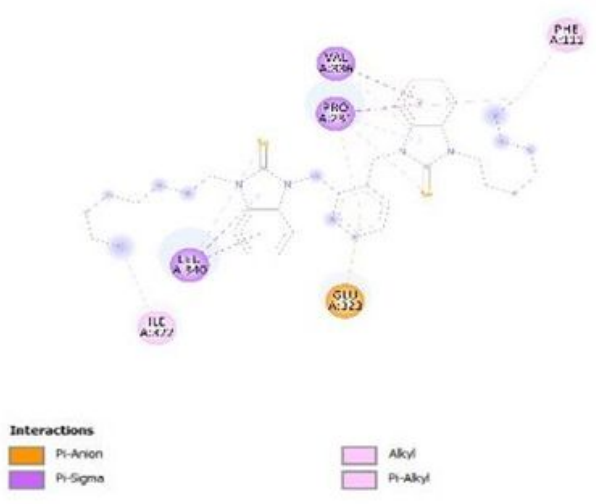

Conformation-1II

Figure 11

Interactions between HIF and Compound 6 


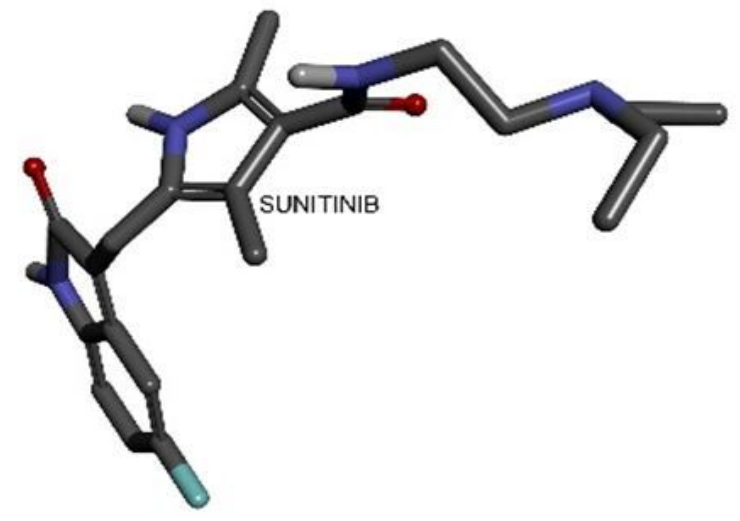

Ligand Structure

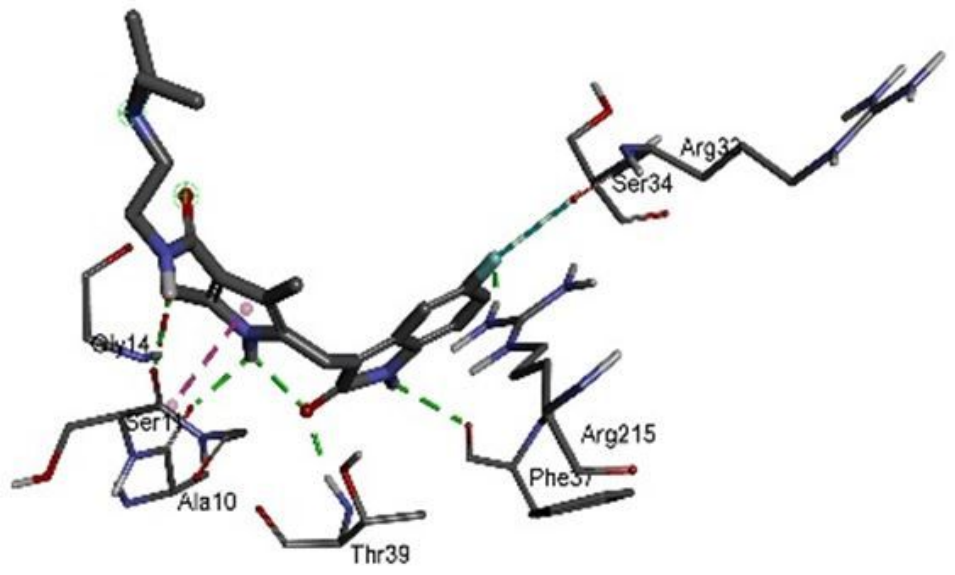

Conformation-1I

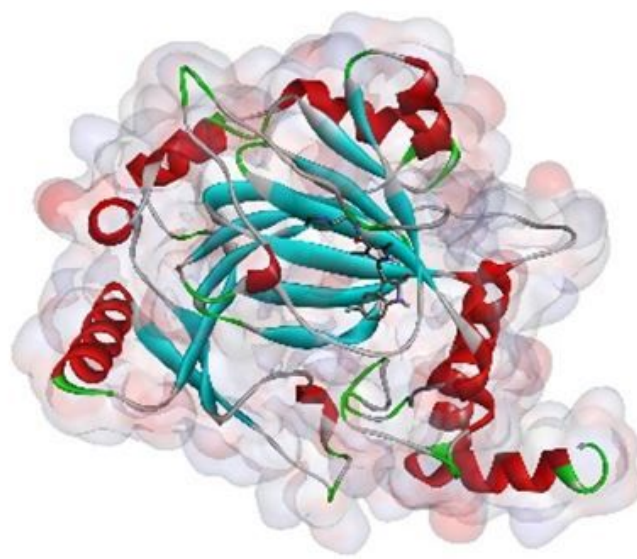

Conformation-1

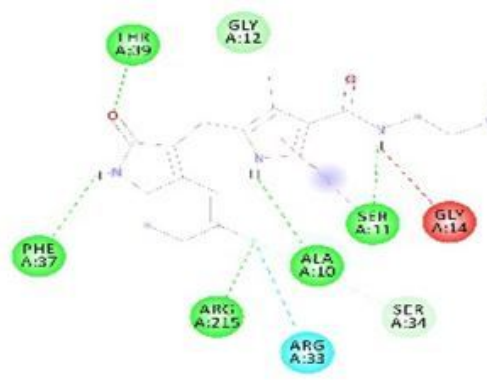

Interactions
\begin{tabular}{|l}
$\square$ van der Waols \\
Conventiond Hydrogen Bond \\
$\square$ Carbon Hydrogen Bond
\end{tabular}

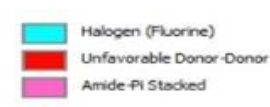

Conformation-1II

Figure 12

Interactions between HIF and sunitinib 


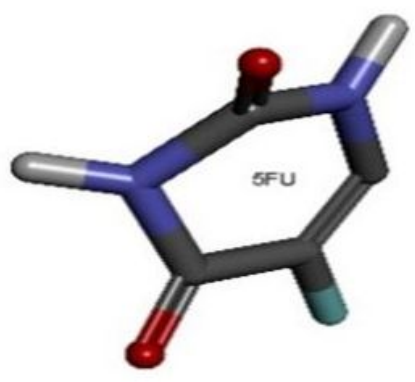

Ligand Structure

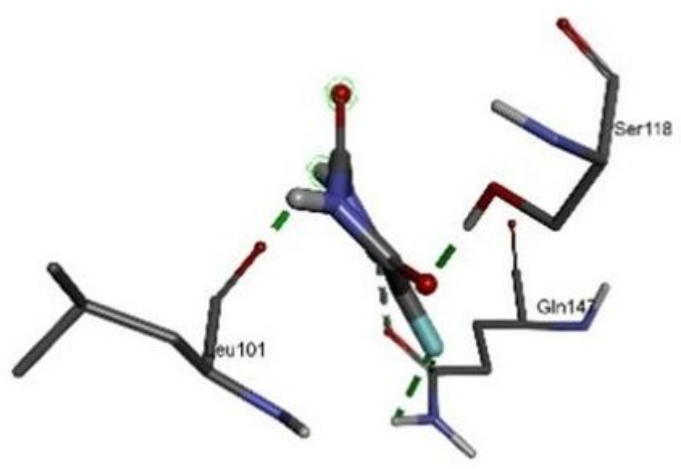

Conformation-1I

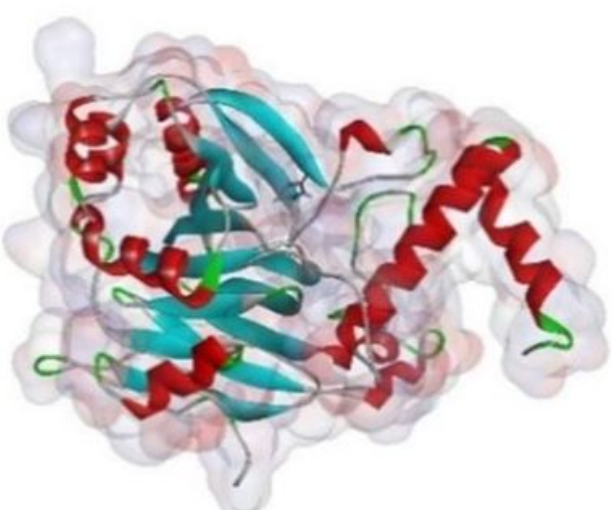

Conformation-1

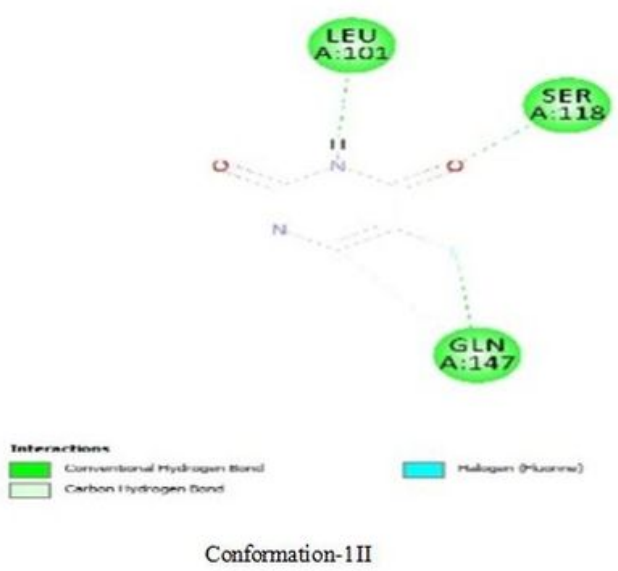

Figure 13

Interactions between HIF and FU 

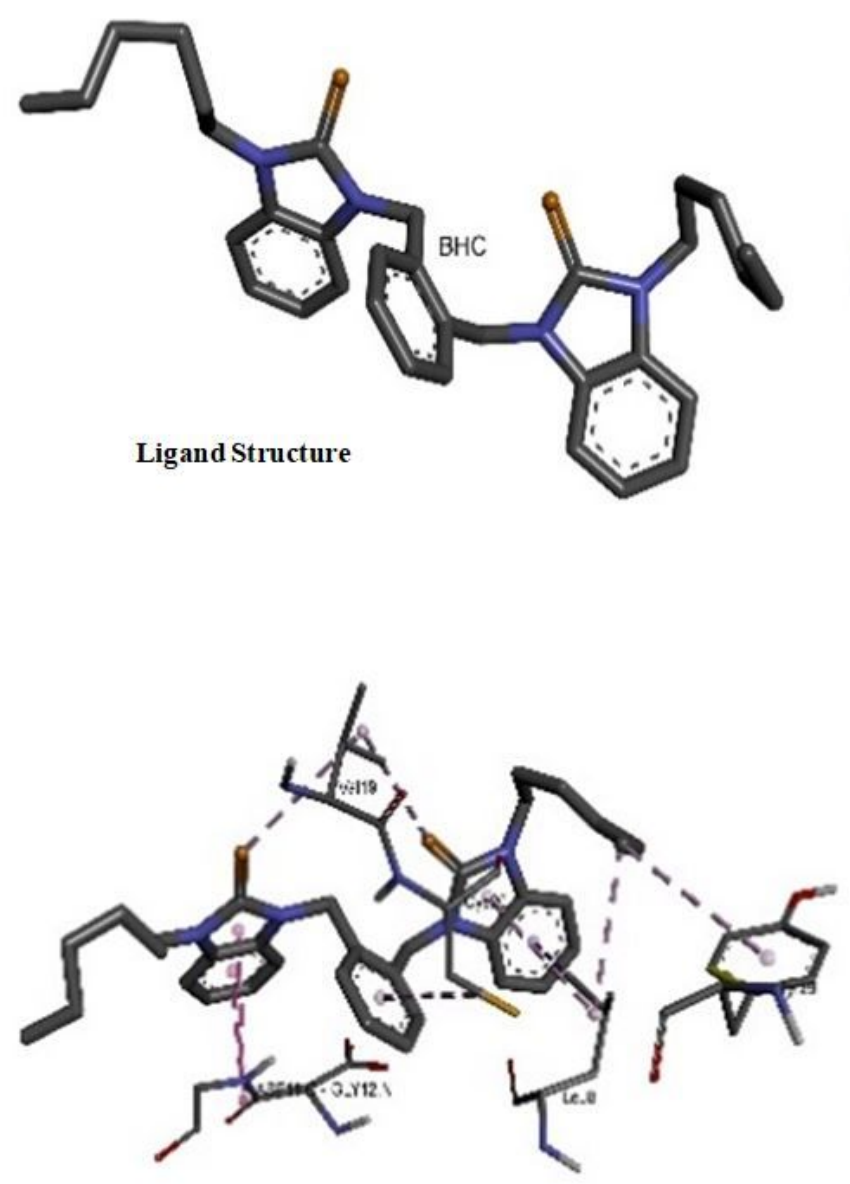

Conformation-1I

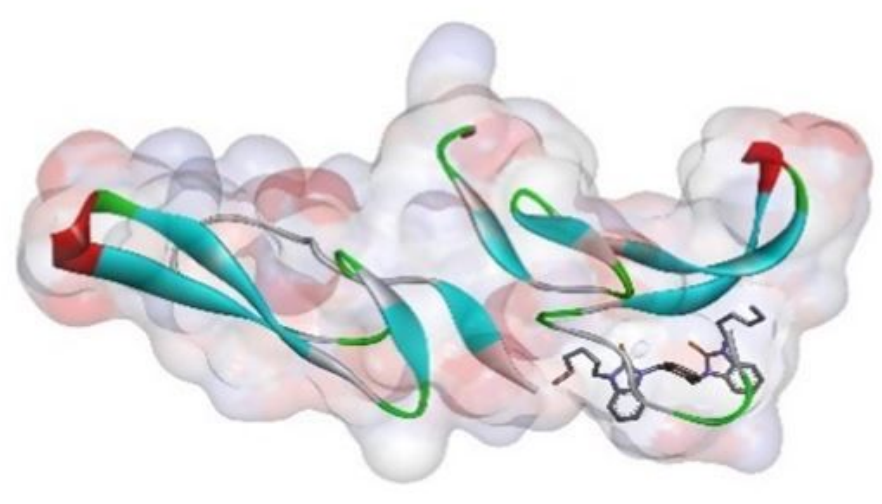

Conformation-1

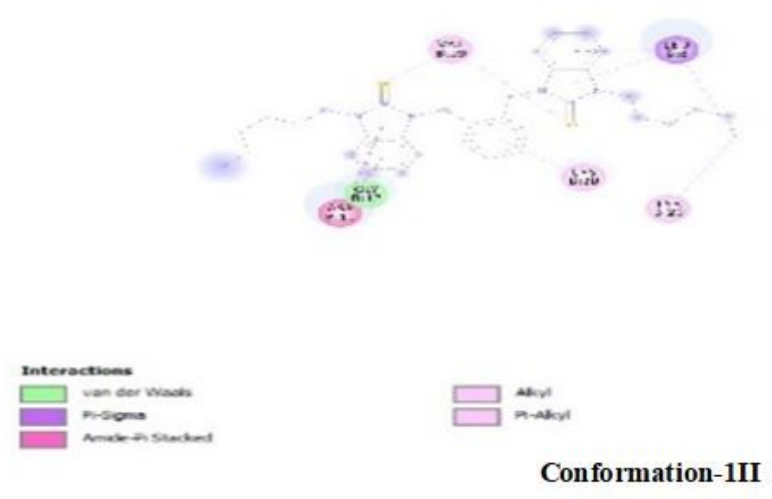

Figure 14

Interactions between EGF with Compound 5 

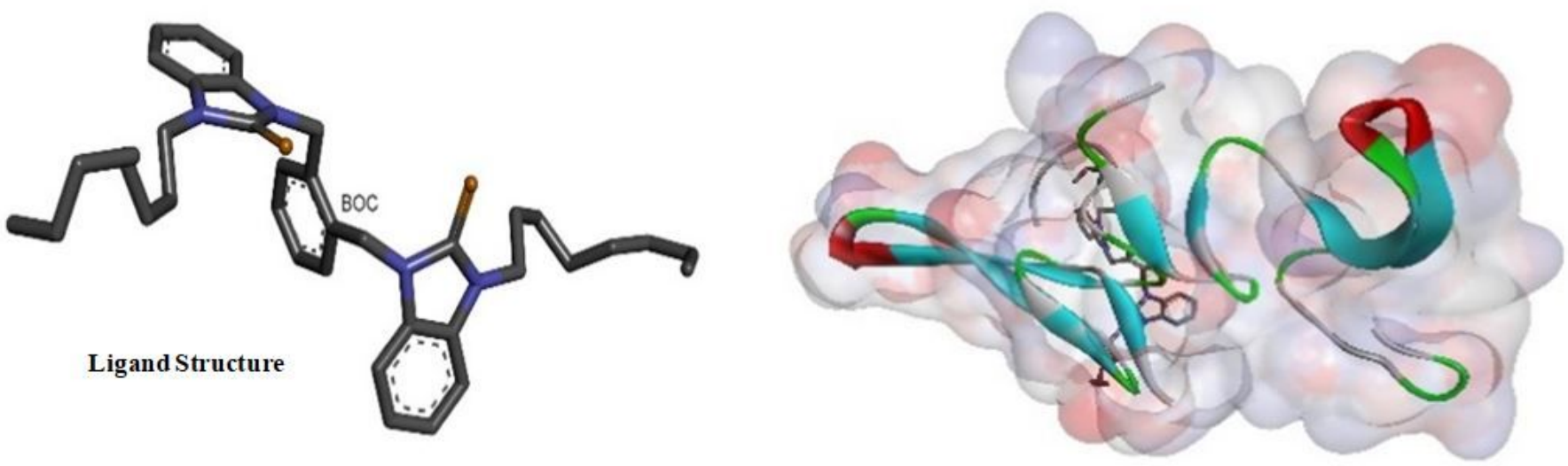

Conformation-1

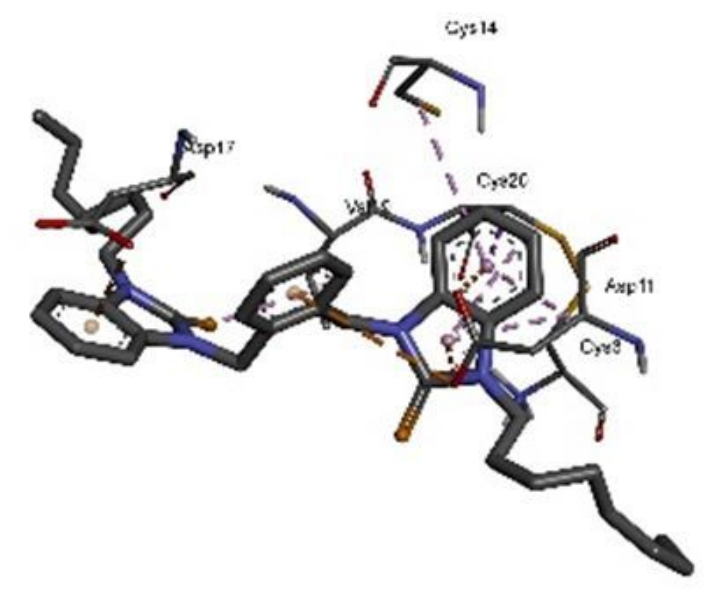

Conformation-1I

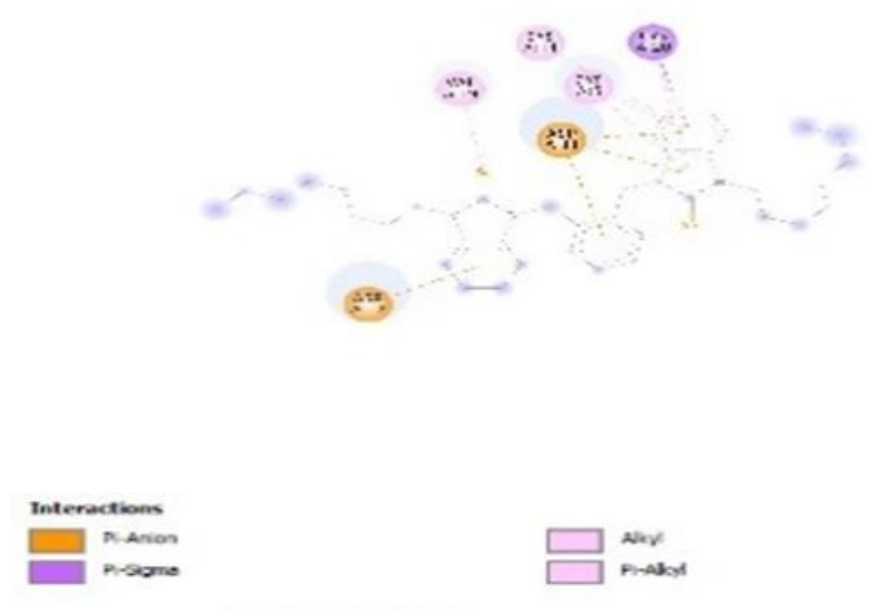

Conformation-1II

Figure 15

Interactions between EGF with Compound 6 


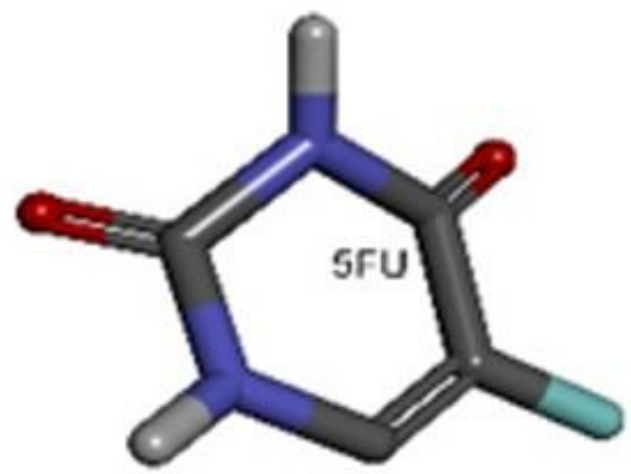

Likand Surasl wers

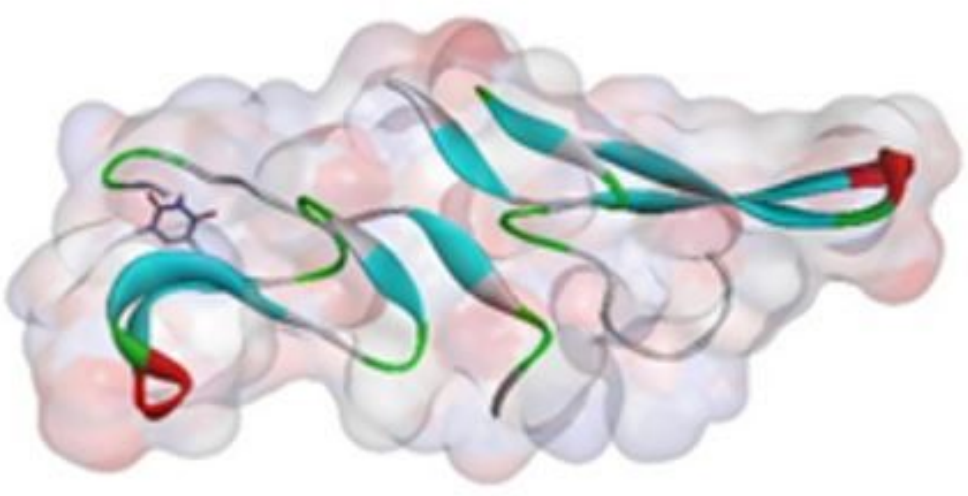

Confoumationt 1

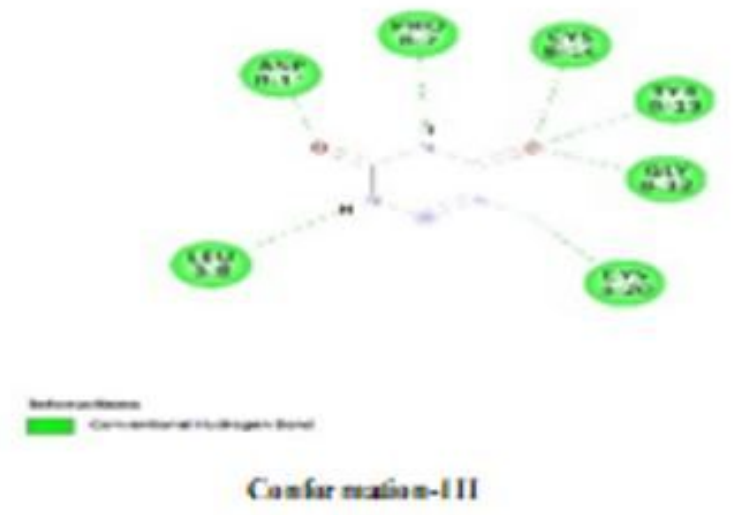

Figure 16

Interactions between EGF with FU 

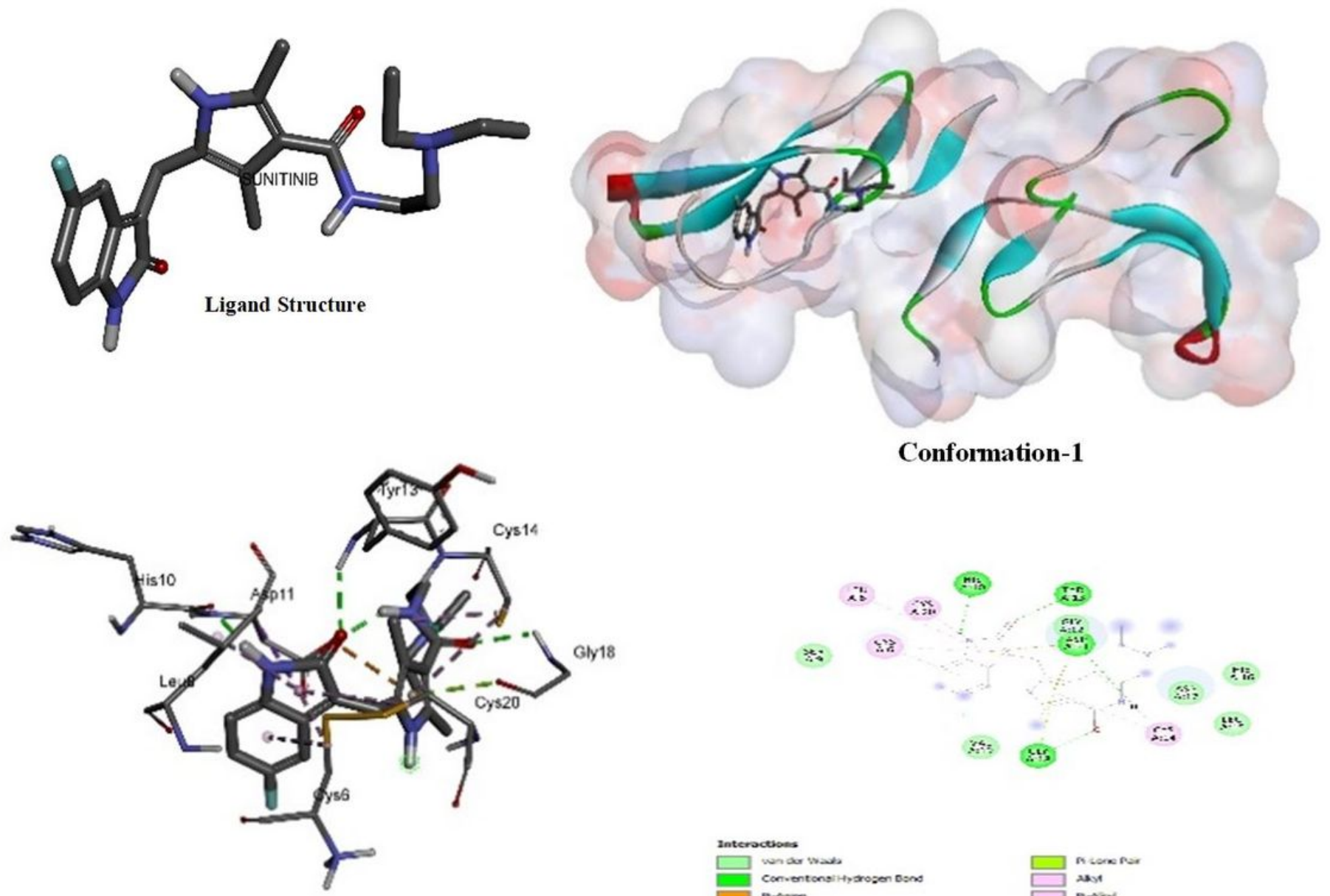

\section{Conformation-1}

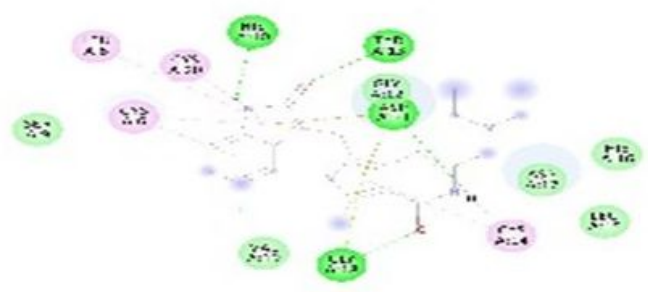

Conformation-1I

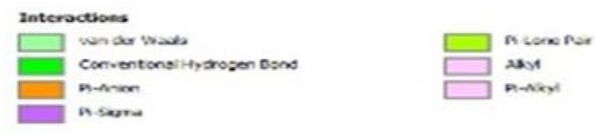

Conformation-1II

Figure 17

Interactions between EGF with sunitinib 


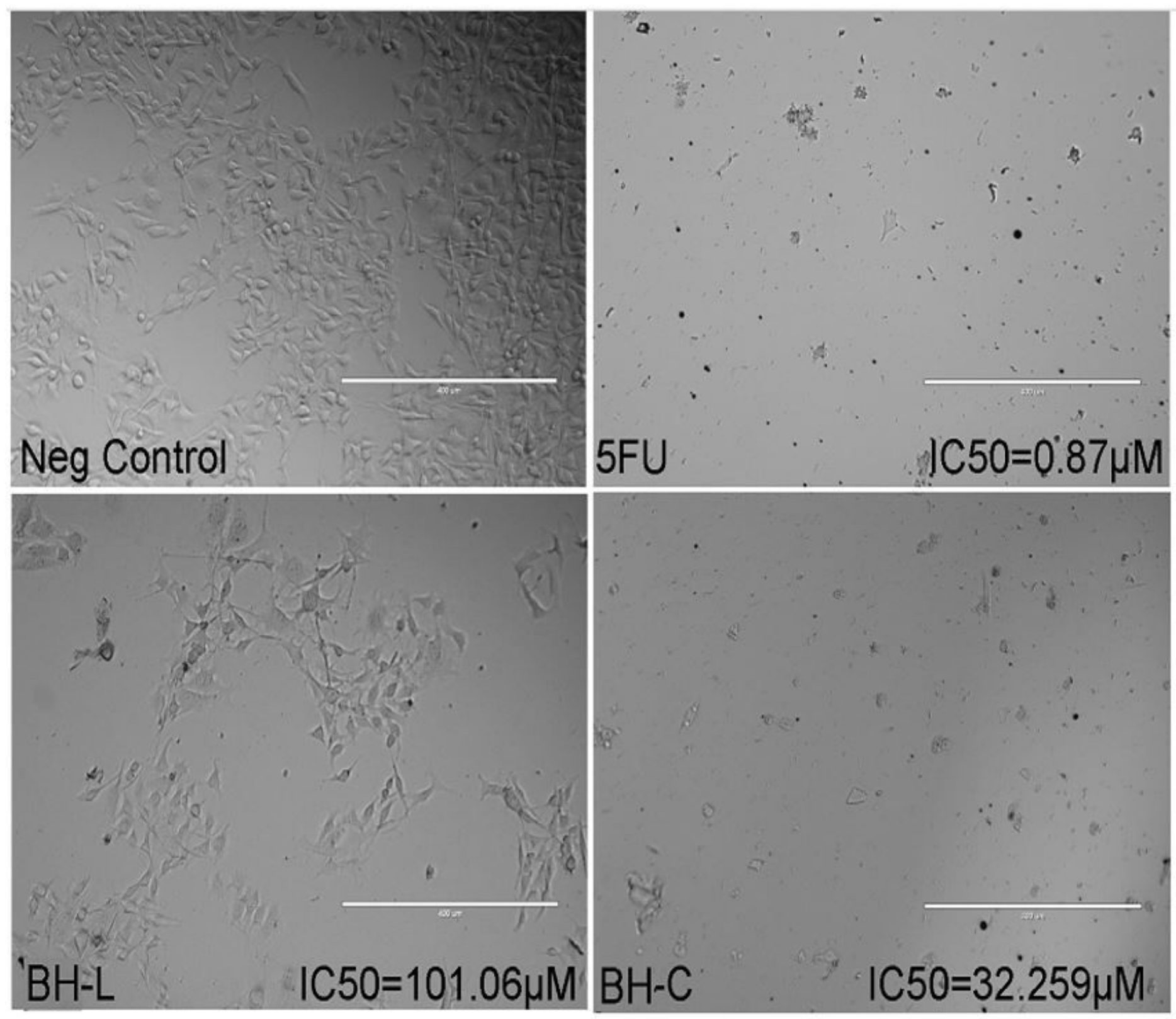

Figure 18

In-vitro Anticancer Activities of $2(\mathrm{BH}-\mathrm{L})$ and $5(\mathrm{BH}-\mathrm{C})$ Against B16F10 


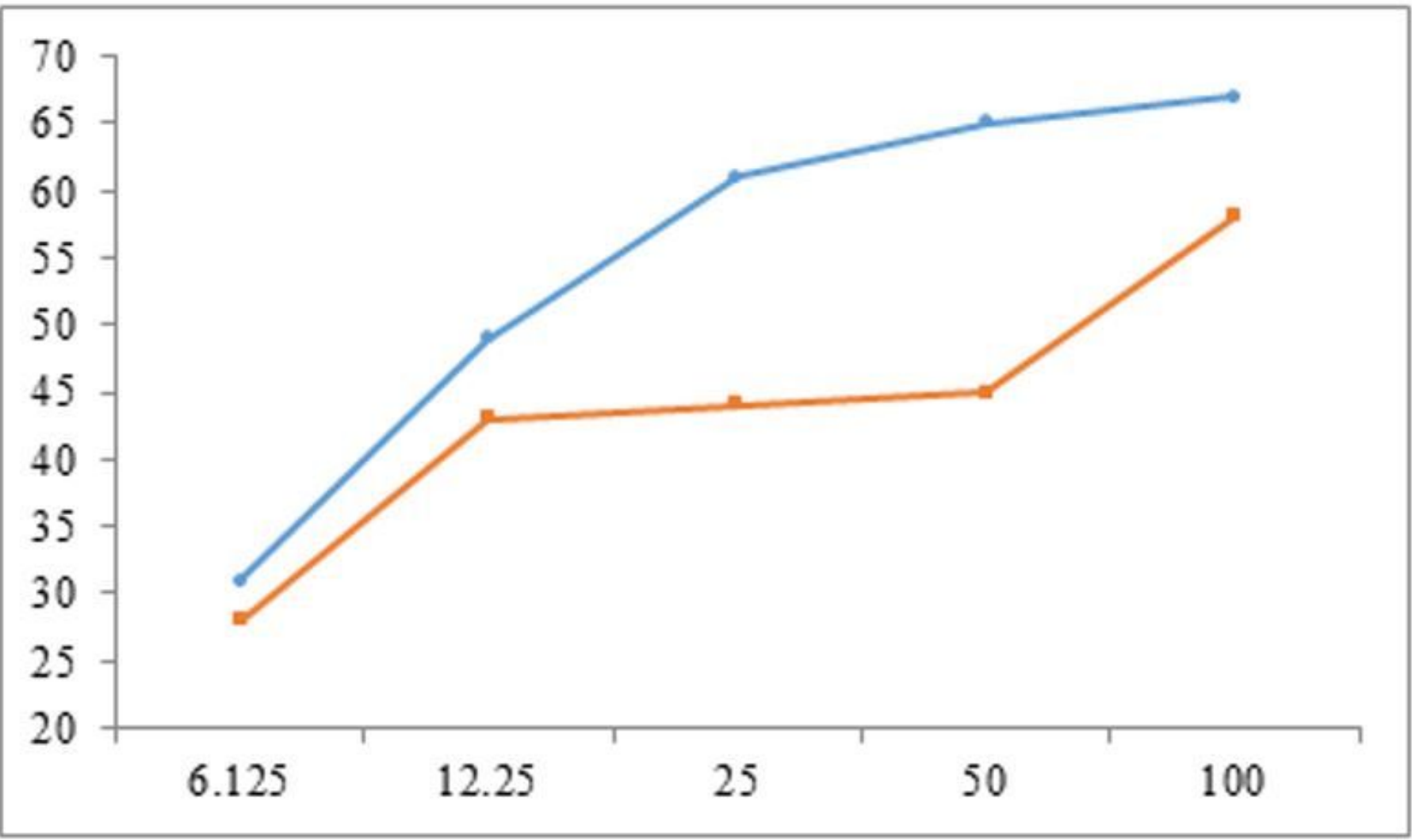

Figure 19

Dose dependence of 2(blue)and 5(yellow)against B16F10 


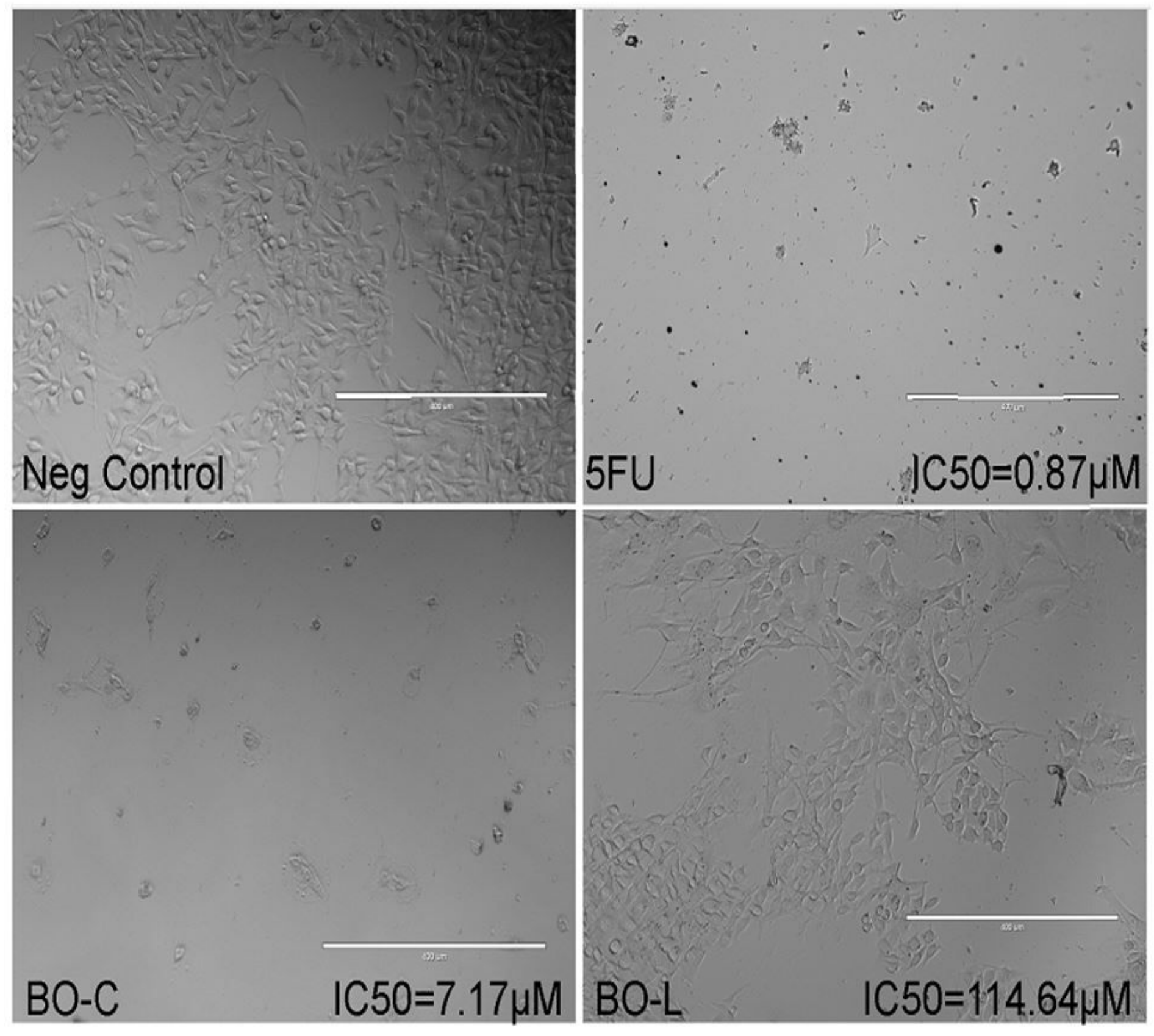

Figure 20

In-vitro Anticancer Activities of 4 (BO-L) and 6 (BO-C) Against B16F10 


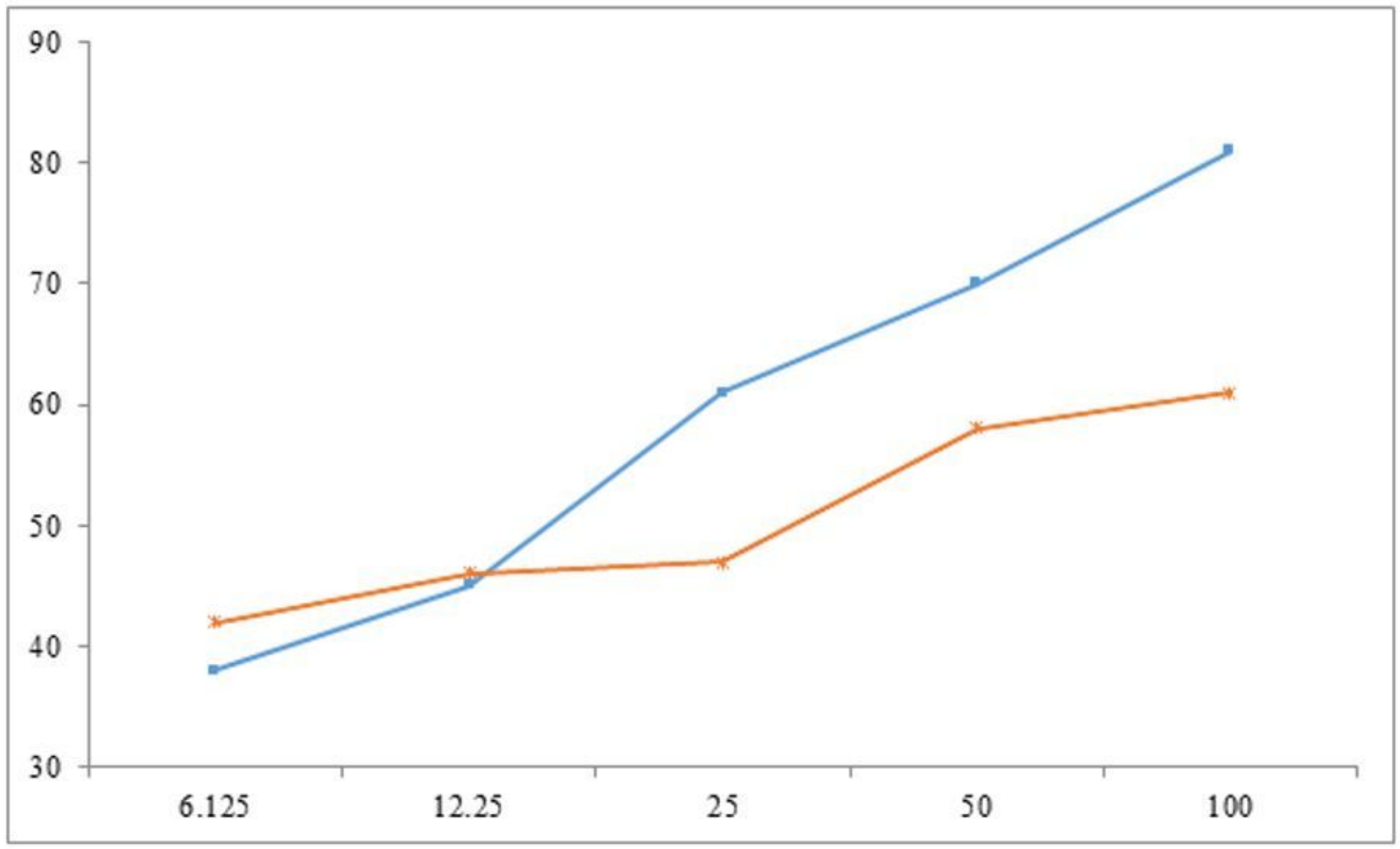

Figure 21

Dose dependence of 4 (yellow) and 6 (blue) compounds against B16F10 


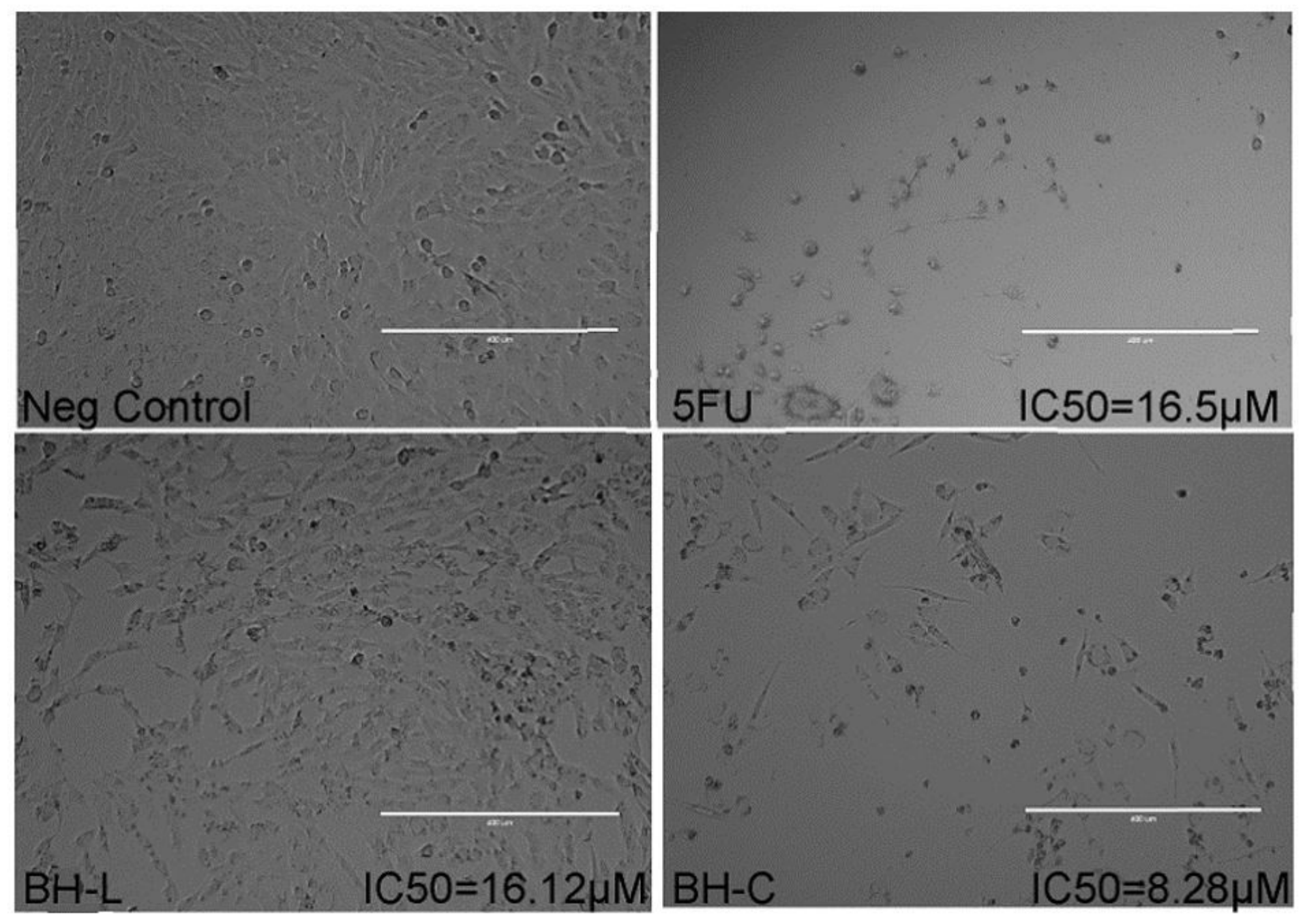

Figure 22

In-vitro Anticancer Activities of $2(\mathrm{BH}-\mathrm{L})$ and $5(\mathrm{BH}-\mathrm{C})$ Against 1-8RGC5 

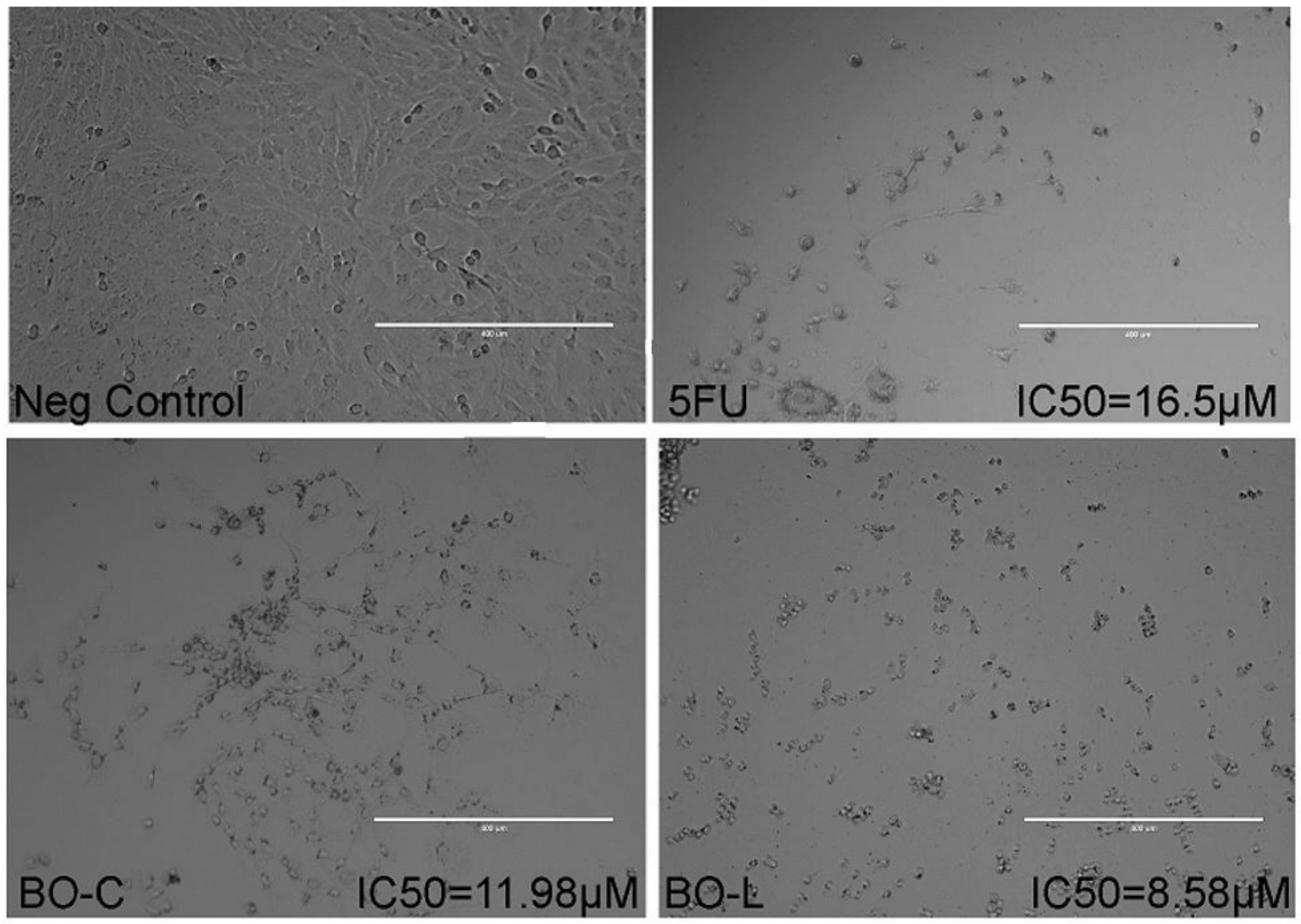

Figure 23

In-vitro Anticancer Activities of 6 (BO-C) and 4 (BO-L) Against 1-8RGC5 

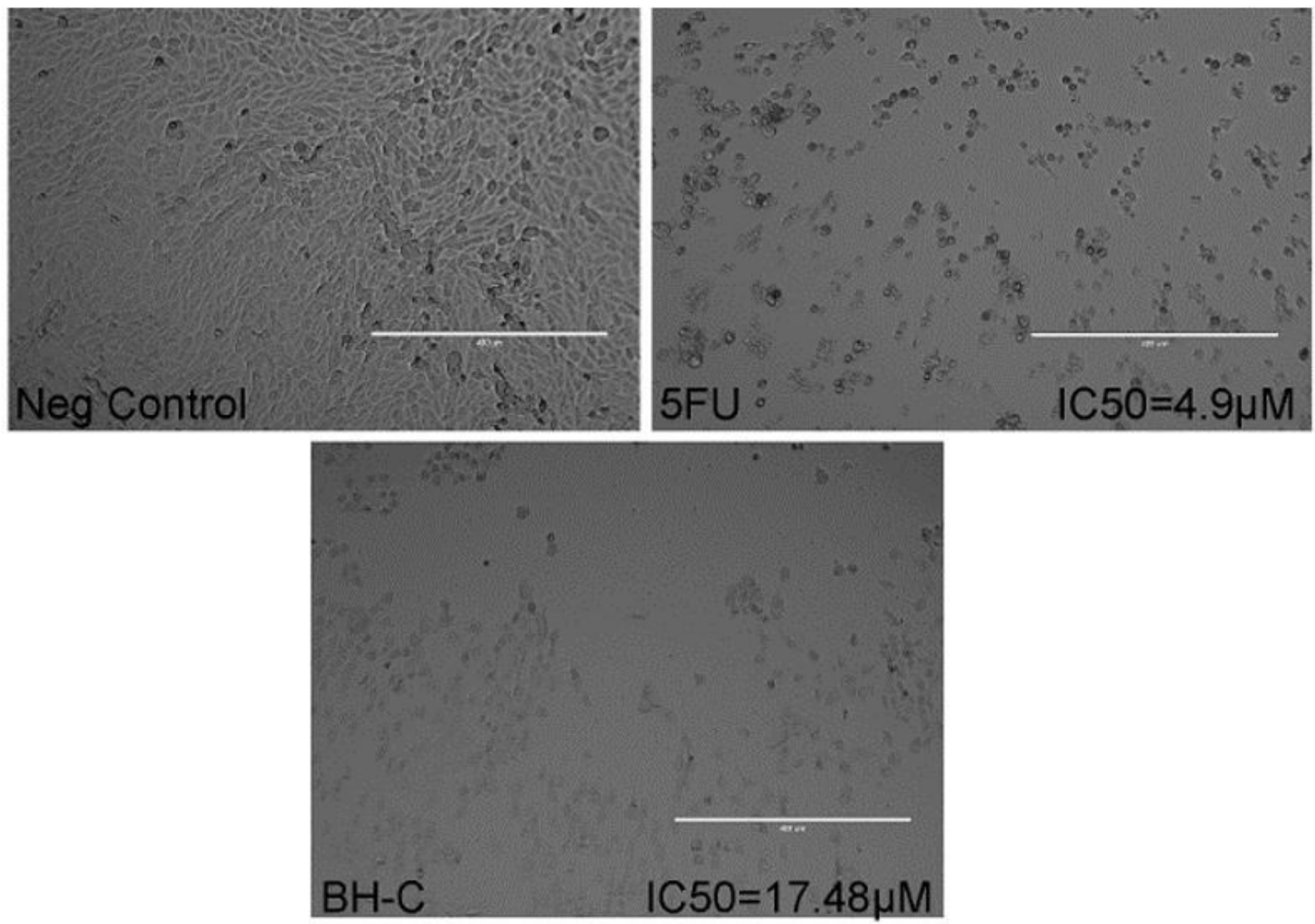

Figure 24

In-vitro Anticancer Activities of $5(\mathrm{BH}-\mathrm{C})$ Against HeLa 


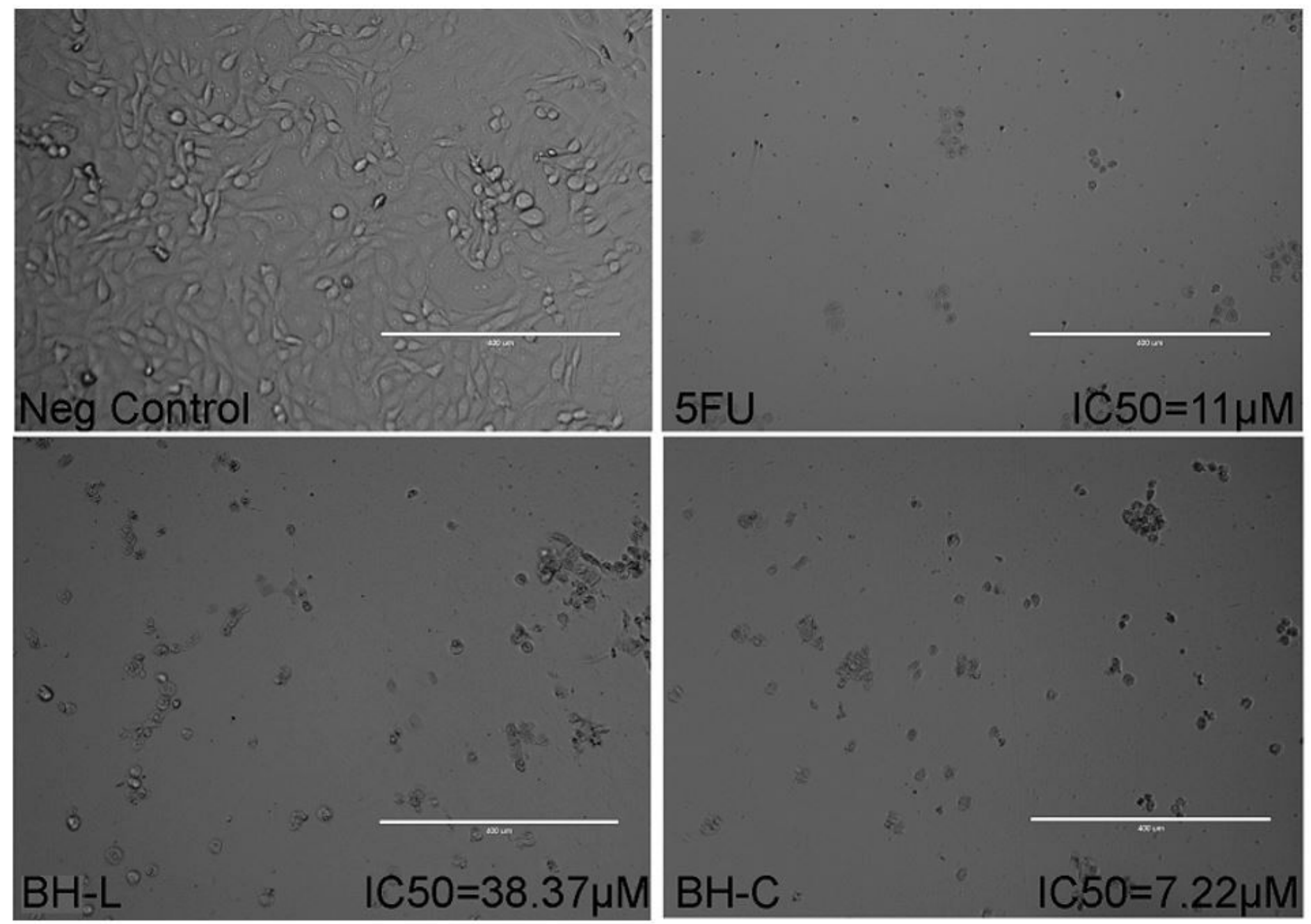

Figure 25

In-vitro Anticancer Activities of 2 (BH-L) and $5(\mathrm{BH}-\mathrm{C})$ against MCF7-1 

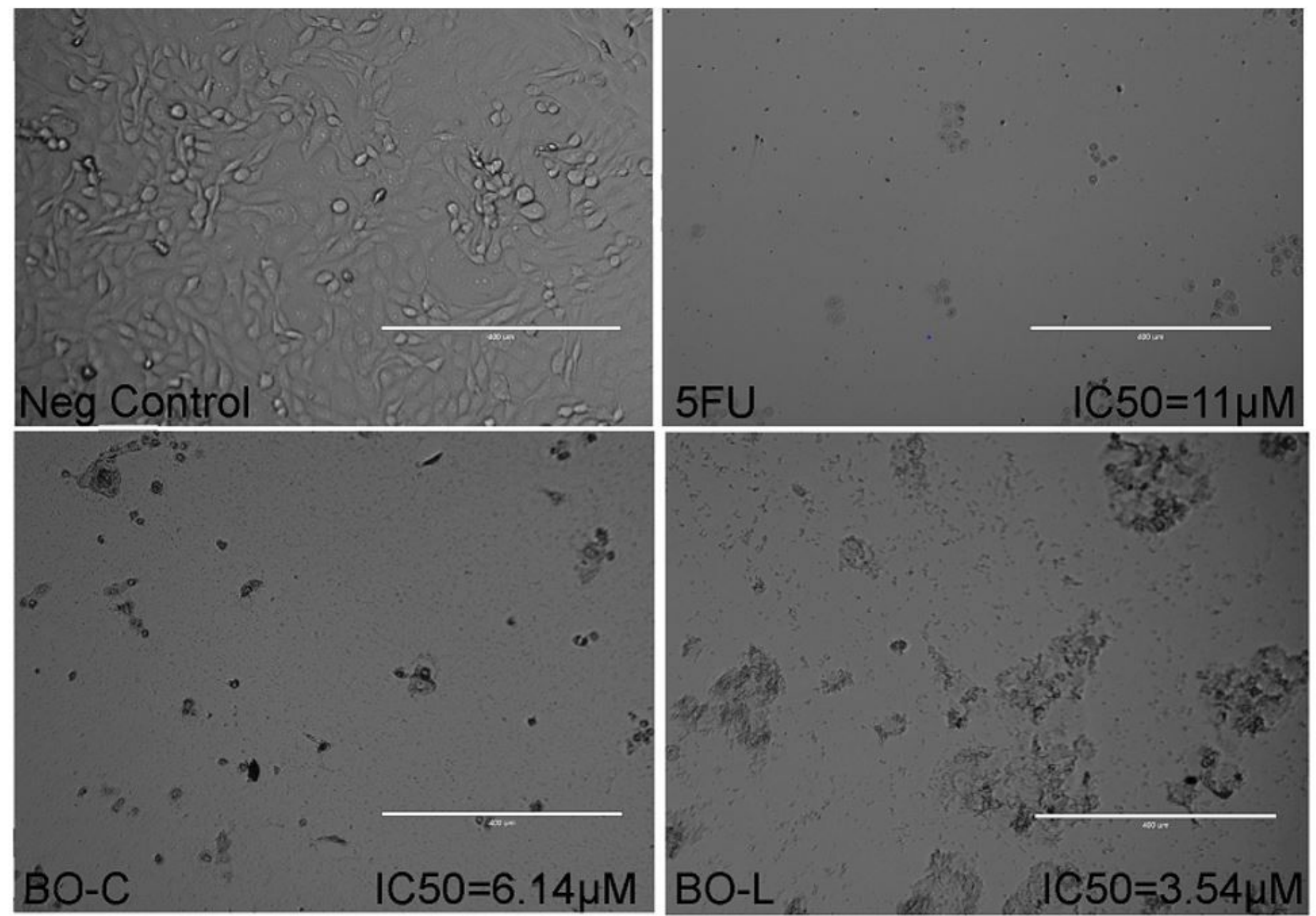

Figure 26

In-vitro Anticancer Activities of 6 (BO-C) and 4 (BO-L) Against MCF7-1

\section{Supplementary Files}

This is a list of supplementary files associated with this preprint. Click to download.

- scheme1.jpg 